ESCRAVOS E TERRAS ENTRE POSSES E TÍTULOS:

A CONSTRUÇÃO SOCIAL DO DIREITO DE PROPRIEDADE NO BRASIL (1835-1889)

Tese de Doutorado

Orientador: Prof. Dr. Samuel Rodrigues Barbosa

UNIVERSIDADE DE SÃO PAULO

FACULDADE DE DIREITO

SÃO PAULO 


\section{ESCRAVOS E TERRAS ENTRE POSSES E TÍTULOS: A CONSTRUÇÃO SOCIAL DO DIREITO DE PROPRIEDADE NO BRASIL (1835-1889)}

Tese apresentada à Banca Examinadora do Programa de Pós-Graduação em Direito, da Faculdade de Direito da Universidade de São Paulo, como exigência parcial para obtenção do título de Doutora em Direito, na área de concentração "Filosofia e Teoria Geral do Direito", sob a orientação do Prof. Samuel Rodrigues Barbosa.

UNIVERSIDADE DE SÃO PAULO

FACULDADE DE DIREITO

SÃO PAULO 
Ao Jeferson, é claro. 


\section{AGRADECIMENTOS}

Três anos e quatro meses. Esse foi o tempo que tive para fazer esta pesquisa e escrever a tese. Como se já não fosse um prazo suficientemente curto, este trabalho também viu um golpe de Estado e a prisão politicamente orientada de um ex-presidente. Além disso, na reta final, tive problemas de saúde que me afastaram completamente da pesquisa por seis semanas. Nesse período, não fui capaz de realizar as tarefas mais básicas, como fazer minha própria comida. Para todas as atividades de cuidado e em todo meu processo de melhora, tive a ajuda inestimável de Jeferson Mariano Silva, Evanir Armond de Oliveira, Raquel Razente Sirotti, Luisa Stella Coutinho, Murat Burak Aydin, Cristian Poczynok, Gaston Pintos Iacono, Marcela Saenz Castro, Karla Luzmer Escobar Hernández, Otto Wilcken, Gilberto Guerra Pedrosa, Laila Scheuch, Johannes Dünnebeil, Denise Garrett, Elisa Frühauf Garcia, Samuel Rodrigues Barbosa, Ricardo Campos, Pedro Henrique Ribeiro, Pamela Cacciavillani, Rosa Congost, Fernanda Bretones, Max Deardorff, Anna Clara Lehmann Martins e Alejandra Ramírez Santos. Os problemas físicos ajudaram a aprofundar outro problema comum em pós-graduandos: crises de ansiedade. Só consegui superá-las com a ajuda profissional de Carolina Lisboa. Sem cada um de vocês, esta tese não seria possível. A todos, meu mais profundo e sincero agradecimento.

Agradeço, também, a todos os funcionários do Arquivo Nacional do Rio de Janeiro, que, contra várias adversidades, fizeram o melhor possível para que eu tivesse acesso à documentação e pudesse realizar a pesquisa. Em especial, agradeço a toda a ajuda de Rosane Soares Coutinho e Rodrigo Mendes Queiroz. Agradeço, ainda, a ajuda de Maurício Dutra, nas últimas semanas da consulta à documentação.

Esta tese não teria tomado os rumos que tomou se não tivesse sido feita no MaxPlanck-Institut für europäische Rechtsgeschichte. Para além da infraestrutura, dos debates regulares e da possibilidade de conhecer pesquisadores do mundo inteiro, o maior benefício para minha pesquisa foi, sem dúvida, a liberdade acadêmica. Por isso, agradeço a Thomas Duve, que sempre demonstrou grande confiança no meu trabalho e não se cansa de me abrir portas. Nesse mesmo sentido, agradeço a meu orientador, Samuel Rodrigues Barbosa, que, desde o mestrado, foi sempre presente e respeitou minhas decisões de pesquisa. 
Também agradeço aos meus colegas no Instituto e, em especial, ao Grupo Latino: Benedetta Albani, Alfonso Alibrandi, Christiane Birr, Manuela Bragagnolo, Pamela Cacciavillani, Otto Danwerth, Max Deardorff, José Luis Egío Garcia, Karla Luzmer Escobar Hernández, Anna Clara Lehmann Martins, Constanza López Lamerain, José María Martín Humanes, Pilar Mejía Quiroga, Osvaldo Rodolfo Moutin, José Luis Paz Nomey e Raquel Razende Sirotti. Tampouco haveria Max-Planck sem o trabalho daqueles que constroem o cotidiano administrativo do Instituto. Por todos, agradeço, especialmente, a Nicole Pasakarnis, Stefanie Rüther, Anna Heym e Tamara Wildmann.

Durante todo o período do doutorado, inúmeros visitantes estiveram no MaxPlanck. A convivência cotidiana com eles ajudou a tornar o trabalho de pesquisa menos solitário. Agradeço, particularmente, a James Almeida, Silvina Alonso Grosso, Alfons Aragoneses, Alexis Alvarez-Nakagawa, Nicolás Beraldi, Pedro Berardi, Ludovica Gabriella Bosica, Álvaro Caso Bello, Natalie Cobo, Alessia Di Stefano, Gisela Ferrari, Elisabetta Fiocchi, Elisa Frühauf Garcia, Enrique González González, Marcella Hayes, Renzo Honores, Antonio Manuel Luque Reina, Massimo Meccarelli, Gilberto Guerra Pedrosa, Gaston Pintos Iacono, Andrés Pletch, Carlos Ramos Núñez, Gustavo Siqueira, Marcela Saenz-Castro, Julia Solla, Michele McArdle Stephens e Alexandra Tellez Mora.

Também foi minha estadia no Max-Planck que me permitiu conhecer excelentes pesquisadoras, com as quais fiz amizades para além da vida acadêmica: Fernanda Bretones, Sol Calandria, Luisa Stella Coutinho, Laura Mazzoni, Fernanda Molina, Laila Scheuch e Leticia Vita. "Eu sozinha ando bem, mas com vocês ando melhor".

Espalhados pelo mundo, agradeço às amigas e amigos de sempre, que me ajudaram a não perder as raízes: Mateus Morais Araújo, Carolina Sapienza Bianchi, Gustavo César Machado Cabral, Tatiana Castro, Davi Collares, Magnum Lamounier Ferreira, João Vitor Loureiro, Maria Júlia Montero, Katarina Pitasse, Bruno Martins Soares e Gustavo Zatelli.

O trabalho acadêmico é tanto melhor quanto mais intensas são as trocas entre pesquisadores. Por isso, agradeço aos amigos que compartilharam comigo suas fontes, bibliografias e ideias: Magdalena Candioti, Adriana Chira, Cristina Dallanora, Soraia Sales Dornelles, Camilla Freitas, Rodrigo Camargo de Godoi, Israel Ozanam, Clemente Penna, Cristian Poczynok, Lucas Rebagliati, Waldomiro Lourenço da Silva Junior e Alain El Youssef. Agradeço, também, a todos que dedicaram parte do seu tempo para comentar resultados preliminares desta pesquisa: Pedro Cardim, Bartolomé Clavero, María Angélica Corva, Rosa Congost, Monica Duarte Dantas, Wim Decock, Tamar Herzog, António Manuel Hespanha, Fernando Martínez Pérez, Joseli Mendonça, Cristina Nogueira da Silva, 
Andréa Slemian e Nomi Stolzenberg. Também agradeço, imensamente, a Ariela Gross, que me recebeu de braços abertos na University of Southern California.

Pela oportunidade de levar a um público mais amplo meu trabalho, agradeço ao convite para participar dos podcasts PODEntender e Salvo Melhor Juízo, este último, coordenado pelo colega Thiago Hansen.

Ao Sidney Chalhoub, agradeço por todo o diálogo e incentivo dos últimos anos. Foi ele quem primeiro levantou a possibilidade de incluir, em minhas pesquisas, o tema da propriedade fundiária. Além disso, sempre se mostrou disponível, participando, inclusive, de minha banca de mestrado, fazendo sugestões que tiveram forte influência na maneira como esta pesquisa foi pensada.

Muitas das ideias que apresento nesta tese foram discutidas e rediscutidas com Manuel Bastias Saavedra e Pedro Cantisano. Com ambos, desenvolvi uma cooperação acadêmica intensa e muito proveitosa. Se sou a responsável pelos eventuais erros deste trabalho, em relação aos acertos, eles compartilham comigo a responsabilidade.

Outra pesquisadora incrível é Raquel Razente Sirotti. Mais do que uma amiga, ela foi uma apoiadora imprescindível nos últimos anos e, em especial, nos últimos meses, nos críticos momentos finais da escrita da tese. Sem Raquel, não consigo nem imaginar a possibilidade dessa tese ter saído da maneira como saiu.

Foram muitas as ajudas que recebi ao longo do caminho, tornando todo esse percurso mais leve. Porém, como mulher e pesquisadora, ainda tenho que enfrentar inúmero obstáculos que meus colegas homens, muitas vezes, ignoram a existência. Lutar, cotidianamente, contra eles não é uma tarefa individual. Nessa empreitada, agradeço, por todo o companheirismo, às integrantes do blog Cientistas Feministas. A história do direito, no Brasil, ainda é um campo dominado, majoritariamente, por homens. Por isso, agradeço também às colegas e companheiras que estão tentando reverter essa situação, especialmente, Laila Maia Galvão, Vanessa Massuccheto, Thais Pinhata e Gabriela Barreto de Sá.

Definitivamente, não teria encaminhado minha carreira do jeito que fiz sem ter cruzado com outras mulheres fundamentais. Elas são fontes de inspiração que me animam a superar os mais diversos obstáculos que nós, mulheres, enfrentamos na academia. Rebecca Scott me acolheu, na University of Michigan, ainda durante o mestrado. A ideia do projeto de doutorado e muitas das questões que levantei nesta tese surgiram dessa experiência de pesquisa e dos debates que tive com ela. Beatriz Mamigonian, além de ser a maior defensora cotidiana de nossa democracia que eu conheço, sempre foi uma 
interlocutora presente, pronta a ajudar com o que fosse necessário, criticando, sugerindo, confiando, incentivando e apostando em meu trabalho. Ao longo desta trajetória, também tive constante apoio e incentivo de Laura Beck Varela, cuja amizade se imiscui com os debates qualificados e divertidos que tivemos ao longo dos últimos anos. Já Mariana Candido, ao me abrir as portas para minha pesquisa futura, acabou por moldar, também, os contornos que a presente tomou. A todas elas, mais do que agradecer, espero, um dia, poder fazer, por outras pesquisadoras, o que elas fizeram por mim.

Em 2018, completo dez anos de pesquisa. Também fazem dez anos que Jeferson Mariano Silva e eu estamos juntos. Não é mera coincidência. A história da minha carreira acadêmica e a história do nosso relacionamento estão intimamente conectadas. Não haveria esta pesquisa sem o namoro e não haveria o namoro sem nossos interesses profissionais em comum. Durante todos esses anos e, especialmente, nessa difícil e conturbada fase final, Jeferson foi um companheiro no mais profundo sentido da palavra. Quando há cumplicidade e convergência sincera de objetivos, a distância é apenas um detalhe passageiro. Por tudo isso, não basta agradecê-lo, porque este trabalho, de certa forma, também é dele. 
Satisfeitos como estamos com a posse, parecemos com medo de olhar para trás, para os meios através dos quais ela foi adquirida, como se temêssemos algum dos elementos em nosso título; ou, na melhor das hipóteses, descansamos satisfeitos com a decisão das leis a nosso favor, sem examinar a razão ou autoridade sobre as quais tais leis foram construídas.

(BLACKSTONE. Commentaries on the Laws of England, p. 1 - tradução minha) 


\section{RESUMO}

DIAS PAES, Mariana Armond. Escravos e terras entre posses e títulos: a construção social do direito de propriedade no Brasil (1835-1889). São Paulo: Faculdade de Direito da Universidade de São Paulo, 2018. 200 p. Tese de Doutorado em Direito.

Esta tese tem como objetivo analisar a construção social das relações entre pessoas e coisas, no Brasil, entre 1835 e 1889. Para tanto, analisei 74 processos que tramitaram perante o Tribunal da Relação do Rio de Janeiro e discutiram a posse e o domínio sobre escravos e terras. No primeiro capítulo, analiso os contornos que a categoria jurídica da posse adquiriu no Brasil oitocentista. Em seguida, passo à análise do papel do reconhecimento social na configuração das situações possessórias. Por fim, descrevo como as interpretações da teoria possessória deslegitimavam atos de uso da terra efetuados por determinados grupos - indígenas e agregados - como aptos a serem considerados atos possessórios. No segundo capítulo, analiso os debates a respeito dos títulos de domínio e o processo de produção de documentos pelas partes, nos processos judiciais. Também analiso o papel das demarcações judiciais nesse processo de produção e como os títulos das mulheres casadas eram frequentemente deslegitimados. Ao final, discorro sobre as novas configurações que os debates acerca da titulação adquiriram nas últimas décadas do século XIX. No terceiro capítulo, analiso situações de aquisições ilegais e irregulares de escravos e terras. Concluo que o processo de construção do direito de propriedade, no Brasil, ao longo do século XIX, aproveitou-se da estrutura pré-existente do direito comum, ressignificando-a.

Palavras-chave: escravidão; terras; propriedade; posse. 


\begin{abstract}
DIAS PAES, Mariana Armond. Escravos e terras entre posses e títulos: a construção social do direito de propriedade no Brasil (1835-1889). São Paulo: Faculdade de Direito da Universidade de São Paulo, 2018. 200 p. Tese de Doutorado em Direito.
\end{abstract}

This thesis aims to analyze the social construction of relations between people and things in Brazil between 1835 and 1889. For this purpose, I analyzed 74 legal proceedings that were processed before the Court of Appeals of Rio de Janeiro and which discussed dominion and possession over slaves and land. In the first chapter, I analyze the contours that the legal category of possession acquired in nineteenth-century Brazil. Then I analyze the role of social recognition in the configuration of possessory situations. Finally, I describe how interpretations of possession theories delegitimized acts of land usage by certain groups - indigenous and aggregates - as possessory acts. In the second chapter, I analyze the debates over domain titles and the process of document production by parties in legal proceedings. I also analyze the role of judicial demarcations in this production process and how titles issued by married women were often delegitimized. In the end, I discuss the new configurations that debates over titles acquired in the last decades of the nineteenth century. In the third chapter, I analyze cases of illegal and irregular acquisitions of slaves and lands. I conclude that the process of construction of private property in Brazil during the nineteenth century built upon the pre-existing structure of ius commune by resignifying its cathegories.

Key words: Slavery; Land; Property; Possession. 


\section{RIASSUNTO}

DIAS PAES, Mariana Armond. Escravos e terras entre posses e títulos: a construção social do direito de propriedade no Brasil (1835-1889). São Paulo: Faculdade de Direito da Universidade de São Paulo, 2018. 200 p. Tese de Doutorado em Direito.

Questa tesi si propone di analizzare la costruzione sociale delle relazioni tra le persone e le cose, in Brasile tra il 1835 e il 1889. In questo modo, io ho analizzato 74 casi che sono stati elaborati presso la Corte di Appello di Rio de Janeiro e que hanno discusso il possesso e il dominio su schiavi e terre. Nel primo capitolo, io analizzo i contorni che la categoria giuridica del possesso ha acquisto nel Brasile del secolo XIX. Poi passo ad analizzare il ruolo del riconoscimento sociale nella configurazione delle situazioni possessorie. Infine, descrivo come le interpretazioni della teoria possessoria hanno delegittimato il uso del suolo da parte di alcuni gruppi - indigeni e aggregati desconsiderando i loro atti come atti possessori. Nel secondo capitolo, io analizzo i dibattiti sui titoli di dominio e il processo di produzione dei documenti da parte delle parti nei processi giudiziari. Analizzo anche il ruolo delle demarcazioni giudiziarie in questo processo di produzione di titoli e come i titoli delle donne sposate siano stati spesso delegittimati. Alla fine, discuto le nuove configurazioni che i dibattiti sulla titolazione hanno acquisito negli ultimi decenni del diciannovesimo secolo. Nel terzo capitolo, analizzo situazioni di acquisizioni illegali e irregolari di schiavi e terre. Concludo che il processo di costruzione del diritto di proprietà, in Brasile, durante il diciannovesimo secolo, ha approfittato della struttura preesistente del diritto comune, risignificandola.

Parole Chiave: Schiavitù; Terre; Proprietà; Possesso. 


\section{LISTA DE FIGURAS}

Figura 1 - Mapa da Província de S. Pedro (1868) 17.

Figura 2 - Mapa da Província de S. Paulo (1868) 48.

Figura 3 - Detalhe do Tractado juridico-practico da medição e demarcação das terras, de Soares (1882) 105.

Figura 4 - Mapa da Província de Minas Gerais (1868) 132.

Figura 5 - Detalhe do Correio Mercantil, de 30 de março de 1857 163. 


\section{SUMÁRIO}

INTRODUÇÃO: SOBRE OCEANOS E COZINHAS 1.

O Atlântico... 1.

... e a cozinha 10.

PLANTAR MANGUEIRAS E MATAR ÍNDIOS: O COTIDIANO DA POSSE ...... 16.

O caso da Fazenda São Joaquim da Boa Vista 16. Posse, uma categoria jurídica 21.

A centralidade do reconhecimento social 29.

Jactum lapidis: atos de contestação da posse 38.

A posse e a arquitetura jurídica da exclusão 43.

O não reconhecimento dos atos possessórios indígenas e seu extermínio _... 44.

Os agregados, a posse e a ideologia senhorial 51.

OCEANO DE PAPÉIS: PRODUZINDO TÍTULOS, CRIANDO DIREITOS 71.

$O$ caso de Felisminda 71.

Mas, afinal, o que era um título? 76.

Produzindo títulos 85.

Produzindo títulos por meio de demarcações judiciais 89.

Invalidando títulos: as mulheres casadas 96.

Títulos e domínio nas últimas décadas do século XIX 104. As demarcações e as novas técnicas 104. Matrículas e escrituras públicas. 108.

TESSITURAS DA LEGALIDADE: AQUISIÇÕES IRREGULARES, TÍTULOS E POSSE 116.

O caso de João, Joaquim e Manuel 116. Ilegalidade e títulos 124.

Circulação e aquisições ilegais 124.

Produção e falsificação de documentos 138.

Ilegalidade e posse 142. 
REFERÊNCIAS BIBLIOGRÁFICAS 168.

Fontes primárias 168.

Arquivo Nacional do Rio de Janeiro 168.

Coleções de jurisprudência 176.

Legislação 176.

Livros de referência 179.

Livros jurídicos 179.

Manuais de agricultores 182.

Periódicos 182.

Projetos de códigos e consolidações 182.

Outros documentos impressos 183. 


\section{INTRODUÇÃO: \\ SOBRE OCEANOS E COZINHAS}

\section{O Atlântico...}

\section{"Ó mar salgado, quanto do teu sal}

São lágrimas de Portugal!'. '

Assim se inicia um dos mais famosos poemas da língua portuguesa, escrito por Fernando Pessoa, no começo do século XX. Nele, Pessoa parece ter se esquecido de que as lágrimas que formaram o Atlântico não foram só portuguesas. Foram, também, americanas e, sobretudo, africanas. Não é possível pensar a história da idade moderna e do início da idade contemporânea sem pensar o Atlântico. E não é possível pensar o Atlântico sem pensar o tráfico de escravos. Um dos pilares fundamentais da expansão marítima europeia, estima-se que, entre os séculos XVI e XIX, o tráfico transatlântico de escravos transportou, forçosamente e de maneiras legais e ilegais, 12 milhões e meio de pessoas da África para a Europa $^{2}$ e, sobretudo, para a América. ${ }^{3}$

Impulsionada pelo tráfico de escravos, a circulação no Atlântico não tinha uma dimensão exclusivamente econômica. O comércio de escravos e bens, em especial, foi consideravelmente volumoso; no entanto, o Atlântico também é marcado por uma significativa integração social e cultural. De um lado a outro, o oceano era cruzado por mulheres e homens, livres e escravos, que levavam consigo, nessas viagens, suas experiências e modos de vida. A cada novo lugar que chegavam, valiam-se dessa bagagem cultural prévia, reformulando-a e ressignificando-a a partir de suas novas condições de vida. Nessa circulação de pessoas, concepções de mundo e práticas habituais, um Atlântico foi sendo construído. ${ }^{4}$

\footnotetext{
PESSOA. Mensagem, p. 29.
}

2 Sobre a escravidão em território metropolitano português, ver GRINBERG; SILVA. "Soil Free from Slaves"; LAHON. "O escravo africano na vida económica e social portuguesa do Antigo Regime"; MARQUES. The Sounds of Silence; PINHEIRO. Em defesa da liberdade; REGINALDO. "África em Portugal"; SAUNDERS. A social history of black slaves and freedmen in Portugal; SILVA. Constitucionalismo e império.

3 Dados disponíveis em Voyages - The Trans-Atlantic Slave Trade Database, consulta em 23 de abril de 2018. 
Concepções acerca de normas, de categorias jurídicas e de justiça também viajavam, nos navios que cruzavam o oceano, junto com as pessoas ou materializados em escritos e documentos. No caso do Atlântico lusófono, havia uma intensa circulação de pessoal burocrático entre os territórios metropolitano e coloniais. Os agentes da Coroa portuguesa transitavam de maneira regular, em razão de um sistema baseado em nomeações temporárias para a ocupação de cargos da administração colonial. Os juristas letrados ocupavam parte importante desses cargos. Em um contexto de sobreposição de ordens normativas e de jurisdições, como era o Atlântico lusófono, a atuação dos juristas letrados portugueses consistiu em gerir essa complexa teia de normatividades, com base em suas habilidades profissionais de criar e interpretar categorias jurídicas. ${ }^{5}$

Característica relevante dessa estrutura burocrática era o fato de que, ao contrário da Coroa espanhola, que fundou universidades na América, Portugal concentrou a formação dos juristas em território metropolitano, por meio da Universidade de Coimbra. Assim, parte relevante do corpo administrativo e político português - e, após a Independência, brasileiro - responsável por gerir a arquitetura institucional no Atlântico lusófono possuía uma formação relativamente homogênea, que contribuía para a criação e conservação de um ambiente jurídico compartilhado na região. ${ }^{6}$

No âmbito da administração secular portuguesa, metropolitana e colonial, a estrutura normativa manejada pelos juristas era o chamado direito comum (ius commune). O direito comum era uma estrutura normativa de caráter marcadamente doutrinário, que esteve presente, em território europeu desde aproximadamente o final do século XI até os séculos XVIII e XIX. Na Europa da idade moderna, o direito comum convivia com outras ordens normativas, como, por exemplo, o direito canônico e o direito dos reinos. ${ }^{7}$

4 ALENCASTRO. O trato dos viventes; CANDIDO. An African Slaving Port and the Atlantic World; CANDIDO. "South Atlantic Exchanges"; FERREIRA. Cross-Cultural Exchange in the Atlantic World; HERZOG. Frontiers of Possession; HẺBRARD, SCOTT. Provas de liberdade, SLENES. “'Malungu, ngoma vem!'”.

5 CAMARINHAS. "Justice Administration in Early Modern Portugal". Neste artigo, o autor também apresenta mapas da circulação dos agentes burocráticos coloniais. Sobre a sobreposição de ordens normativas, ver DUVE. "Was ist 'Multinormativität'?". Para uma discussão entre as diferentes jurisdições existentes em Angola, durante os primeiros séculos do período colonial, ver MADEIRA-SANTOS. "Esclavage africain et traite atlantique confrontés". Para os séculos XIX, ver SILVA. A construção jurídica dos Territórios Ultramarinos Portugueses no século XIX.

6 Sobre a formação dos juristas lusófonos, ver CARVALHO. A construção da ordem/Teatro de sombras, pp. 63-92 e ROBERTO. O direito civil nas Academias Jurídicas do Império.

7 DECOCK. Theologians and Contract Law, pp. 30-31, HESPANHA. "Direito comum e direito colonial". 
A lógica de construção e funcionamento do direito comum era bastante diferente da do direito atual, de matriz liberal. A arquitetura do direito comum se construía por meio de textos nos quais os juristas apresentavam suas soluções para problemas. Assim, em geral, a construção de categorias jurídicas era feita por meio da proposta de possíveis soluções e interpretações para conflitos concretos. Nesse sistema normativo, a lei escrita não era uma fonte do direito hierarquicamente superior às outras, podendo ser contestada e reformulada pela prática dos tribunais e pelas interpretações doutrinárias. $\mathrm{Na}$ decisão dos casos concretos, as normas não tinham força absoluta, mas eram avaliadas pelos juízes "arbítrio do juiz" - que, analisando as particularidades do caso e recorrendo a diversas fontes do direito, deveria decidir com vistas à equidade. Em sua estrutura, o direito comum era aberto e flexível à interação com outras ordens normativas e com particularidades locais. Essa flexibilidade do direito comum foi o que, em certa medida, permitiu sua expansão relativamente eficaz para os territórios coloniais. ${ }^{8}$

Em termos estritamente legislativos, havia certa coincidência entre a legislação aplicada na metrópole e nos territórios coloniais portugueses. Apesar de parte das normas emanadas pela Coroa ter um caráter específico, dirigido apenas a uma região, é possível encontrar cópias dessas normas específicas em outros territórios coloniais, o que denota que, mesmo nesses casos, havia uma relativa circulação dos textos legislativos. Considerando as normas de caráter geral, é muito importante ter em conta que elas não se trasladavam por si sós. Havia diversos agentes envolvidos nessa difusão: juízes de fora, juízes ordinários, governadores, capitães donatários, membros do clero, missionários, etc. Por meio desses agentes, normas isoladas e compilações de legislação como, por exemplo, as Ordenações Filipinas, tinham razoável disseminação tanto na América quanto em outros territórios, como a África. Essas normas eram publicizadas por meio de sua leitura em locais públicos, nas missas de domingo e em reuniões de confrarias e irmandades. ${ }^{9}$

Ainda que eminentemente letrado, o direito comum se disseminava por compreensões e hábitos populares. Sua disseminação era garantida pela própria maneira a partir da qual era estruturado. Muitos dos textos jurídicos eram compostos por uma grande quantidade de brocardos, frases curtas que enunciavam uma norma. Isso facilitava sua

8 HESPANHA. "Direito comum e direito colonial". Ver, também, CABRAL. Literatura jurídica na idade moderna; GARRIGA. "Orden jurídico y poder político en el Antiguo Régimen”; GROSSI. El orden jurídico medieval; TAU ANZOÁTEGUI. Casuismo y sistema; VALLEJO. Ruda equidad, ley consumada; VALLEJO. "El cáliz de plata".

9 BALTAZAR, CARDIM. “A difusão da legislação régia”. 
comunicação oral e sua fixação. Também era expressado por fórmulas reproduzidas em documentos oficiais por notários, outra característica que facilitava a permeabilidade desse saber técnico nos discursos mais corriqueiros e tornava possível que ele fosse reapropriado, mobilizado e ressignificado pelos mais diferentes sujeitos históricos, que iam construindo entendimentos vernaculares das normas do direito comum. ${ }^{10}$

Vejamos, por exemplo, o caso do Alvará, de 16 de janeiro de 1773, analisado por Luiz Geraldo Silva. Esse ato normativo estabeleceu, em linhas gerais, que todos os que nascessem, em território metropolitano, depois de sua publicação, seriam livres. Analisando a documentação referente à cidade de Paraíba de Senhora das Neves, na América Portuguesa, o pesquisador encontrou uma carta do ouvidor da cidade endereçada ao governador, dizendo:

...participo a Vossa Excelência que havendo-se espalhado na Cidade da Paraíba, a Lei porque Sua Majestade foi servido Libertar os mulatos e pretos de Portugal, tem sido tão mal entendida pelos mulatos, e negros daquela Cidade, que tem chegado a fazer entre eles conciliábulos e conventículos, de sorte que a interpretaram, e publicam a seu favor, tirando inúmeras cópias, vendendo-as a preço de uma pataca, e faltando sobre a inteligência da mesma Lei. $^{11}$

Com medo de que os escravos da cidade, a partir da interpretação que estavam fazendo da legislação metropolitana, começassem a reivindicar sua liberdade, as autoridades locais iniciaram uma devassa para averiguar o caso. A análise feita por Silva do processo elucida os diversos meios pelos quais as normas jurídicas circulavam entre a população e como, a partir de sua leitura ou escuta, iam-se formando entendimentos vernaculares das mesmas. As testemunhas deram muitas versões do fato. Uma delas disse que um "mulato" vendia cópias da lei a uma "pataca". Ressalvou, porém que essa "cópia" tinha sido escrita na língua do "mulato" - que mesclava elementos de línguas africanas com o português -, mas que o conteúdo não estava muito distante ao "espírito original" da lei. Outra disse que o grande tema de debate era se a expressão "seus domínios" se aplicaria ou não à América Portuguesa, o que, em caso positivo, significaria a libertação do

10 HESPANHA. Como os juristas viam o mundo, pp. 12-13. Como exemplo de permeabilidade dos discursos letrados do direito comum, ver HERZOG. Frontiers of Possession.

11 Apud SILVA. "Esperança de liberdade”, p. 128. 
ventre. Vários depoimentos confirmaram que a lei era lida por grupos de negros que se encontravam na Praia do Tambaú. Também ficou evidente que, além dessas leituras públicas, cópias da lei circulavam de mão em mão, com um conhecido passando para o outro após terminar a leitura. Houve, ainda, quem afirmou que cópia do Alvará tinha chegado, à cidade, por meio de uma carta enviada da Bahia. Como reação, o governador de Pernambuco mandou publicar um Bando informando a população da "verdadeira interpretação" do Alvará. ${ }^{12}$

Assim como os negros da Paraíba, em ambos os lados do Atlântico, as pessoas construíam noções vernaculares das normas e as transportavam com elas quando se locomoviam na região. Afinal, não eram só os burocratas que circulavam de um lado a outro. Apesar de muitas vezes não serem "letrados", essas mulheres e homens, livres, libertos e escravos tinham concepções próprias de justiça e acessavam, em alguma medida, as normas, reinterpretando-as, mobilizando-as em situações de conflito e pautando, por elas, suas práticas cotidianas. ${ }^{13}$

Além do mais, as questões que envolviam escravidão e liberdade perpassavam a vida todas as pessoas, não apenas na medida em que interessavam imediatamente a escravos e senhores, mas estruturando todas as relações sociais. $\mathrm{Na}$ arquitetura institucional do direito comum, os conflitos em torno da liberdade, ao chegarem aos tribunais estabelecidos nas diferentes regiões do Atlântico, eram traduzidos na linguagem jurídica pertinente à regulação das relações entre pessoas e coisas. Nesse sentido, no Atlântico lusófono, a linguagem da liberdade era a linguagem da "propriedade". Ou seja, a estrutura do direito comum sobre a relação entre pessoas e coisas geria tanto o estatuto jurídico das pessoas - liberdade, escravidão ou outras formas de dependência - quanto os atos de aquisição e uso dos bens.

Como identificou Rosa Congost, há uma tendência, nos textos da área de história agrária, de reproduzir, em certa medida, uma visão da propriedade muito conectada com o discurso liberal sobre esse instituto. ${ }^{14}$ Em muitos trabalhos, é frequente que a noção de

12 SILVA. "Esperança de liberdade".

13 Sobre circulação de escravos, libertos e outros grupos "não letrados", no Atlântico, ver CANDIDO. "South Atlantic Exchanges"; CARVALHO; GOMES; REIS. O Alufá Rufino; LINEBAUGH; REDIKER. The Manyheaded Hydra; MAMIGONIAN. "José Majojo e Francisco Moçambique, marinheiros das rotas atlânticas"; SLENES. "Malungu, ngoma vem!'”. Sobre as concepções vernaculares, a respeito das normas jurídicas, dessas pessoas, ver HÉBRARD; SCOTT. Provas de liberdade; HERZOG. Frontiers of Possession; PREMO. The Enlightenment on Trial.

14 CONGOST. Tierras, leyes, historia, pp. 11-43. 
propriedade individual norteie as análises, mesmo quando se trata de períodos em que não era propriamente esse instituto o que regulava as relações entre pessoas e coisas. Como venho argumentando, a estrutura do direito comum era completamente diferente da do direito que foi sendo construído a partir de finais do século XVIII. A maneira como o direito comum normatizava as relações entre pessoas e coisas partia de pressupostos distintos daqueles em que se baseia o direito liberal. Naquela arquitetura normativa, não havia nada próximo à ideia de propriedade individual como direito subjetivo hierarquicamente superior aos demais direitos sobre os bens.

No direito comum, a noção jurídica de "coisa" era bastante ampla, englobando, além do que hoje identificamos como tal, ações, direitos, pessoas e, até mesmo, alguns fatos. Vale ressaltar, ainda, que o tratamento jurídico das pessoas como coisas extrapolava o caso mais evidente da escravidão. Ações e obrigações de determinadas pessoas, como, por exemplo, as obrigações de trabalhar, de obedecer, de se sujeitar ao mando de outrem, dentre outras, poderiam ser consideradas como coisas integradas a um determinado patrimônio e, portanto, estar sujeitas ao tratamento jurídico dispensado aos bens materiais. Ou seja, não havia uma distinção clara entre pessoas - sujeitos de direitos - e coisas objetos de direitos - , como há no direito liberal. ${ }^{15}$

Como os direitos e os estados das pessoas eram considerados coisas imateriais, eles tinham um regime semelhante ao dos bens e poderiam ser protegidos por tipos similares de ações. ${ }^{16}$ A liberdade estava compreendida entre esses estados sobre os quais incidiam normas referentes às relações jurídicas entre pessoas e coisas.

$\mathrm{O}$ que estava subjacente a essas construções jurídicas era uma ideia de que havia uma pluralidade de estatutos naturais, na ordem do mundo, que determinavam os direitos e obrigações de cada ente, animado ou não. Nessa ordem "natural", que estruturava as relações entre as pessoas e as coisas, tudo tinha uma finalidade e, portanto, uma utilidade. A essa ordem da utilidade, correspondia uma ordem da necessidade, segundo a qual os usuários deveriam desfrutar das coisas de maneira legítima e de acordo com o direito.

15 GROSSI. Il dominio e le cose, pp. 57-122; HESPANHA. Como os juristas viam o mundo, pp. 307-314. Sobre a coisificação de pessoas, de seu trabalho e de suas obrigações, ver CONTE. Servi medievali; WIESE. Leibeigene Bauern und Römisches Recht im 17. Jahrjundert.

${ }^{16}$ HESPANHA. Como os juristas viam o mundo, pp. 307-314; TESTUZZA. "Ius corporis, quase ius de corpore disponendi". 
Assim, "domínio" era "o poder ou a faculdade reconhecido a alguém de se apoderar das coisas, pondo-as à sua disposição e uso lícito". ${ }^{17}$

O domínio, como faculdade de uso, era uma categoria jurídica bastante ampla, que abarcava diversos direitos de gozo sobre as coisas, como usufruto, hipoteca, servidão, etc. Ele também poderia abranger direitos de gozo sobre pessoas como, por exemplo, o exercício da jurisdição. Nesse sentido, o domínio não tinha como objeto a coisa em si, mas uma de suas utilidades. Como as utilidades das coisas poderiam ser muitas, também o domínio poderia ser múltiplo, abrangendo as diferentes faculdades de uso das coisas, não havendo uma hierarquia entre os diferentes tipos de domínio. Tampouco havia hierarquia entre os diferentes direitos que poderiam coexistir sobre a mesma coisa. O domínio, portanto, não era um direito "hierarquicamente superior", "que valia mais" do que os demais que incidiam sobre as coisas. Além disso, o dono, o detentor do domínio, poderia usar das coisas como bem lhe aprouvesse contanto que não existissem outros domínios ou outros direitos incidindo sobre elas. Ou seja, o domínio não era um direito exclusivo e ilimitado. ${ }^{18}$

Não havia, também, identificação entre as palavras "dominium" e "propietas". O domínio tinha um sentido amplo, abarcando tudo o que pudesse estar sujeito ao poder de um "dominus", ou seja, poderia abarcar o que estivesse sujeito ao poder desde um rei até um pai de família. Assim, domínio dizia respeito a ter poder sobre coisas - que, como vimos, poderiam abarcar, também pessoas e direitos -, enquanto "propietas" se referia à atribuição de determinados objetos a pessoas. Essa concepção era, também, mais ampla do que a noção contemporânea de propriedade, porque poderia abarcar, por exemplo, a propriedade de cargos. ${ }^{19}$

Outra característica do domínio - e dos outros direitos que incidiam sobre as coisas - era que ele não estava separado do uso efetivo da coisa. Assim, a arquitetura normativa do direito comum procurava privilegiar, em situações de conflitos, as partes que estivessem efetivamente usando a coisa, exercendo posse sobre ela. Uma vez que um dos objetivos dessa ordem jurídica era a manutenção do status quo, nada mais coerente do que proteger

${ }_{17}$ GROSSI. Il dominio e le cose, pp. 21-56, 123-190, 247-272; HESPANHA. Como os juristas viam o mundo, p. 312 .

${ }^{18}$ GROSSI. Il dominio e le cose, pp. 21-56, 123-190, 247-272; HESPANHA. Como os juristas viam o mundo, pp. 311-316.

19 WILLOWEIT. "Dominium und Proprietas". 
aquele que, no momento do conflito, era o detentor estável e contínuo da coisa, fosse ela material ou imaterial. ${ }^{20}$

A ordem normativa do direito comum, no entanto, começou a ser questionada na "Era das Revoluções". Desde o chamado "iluminismo jurídico" até as reformas liberais empreendidas pelos nascentes Estados Nacionais ao longo dos séculos XIX e XX, diversas foram as propostas de reformulação dos sistemas jurídicos. Em linhas gerais, tais propostas não mais fundavam o direito em uma ordem divina e natural que deveria ser preservada, mas no pressuposto de que a sociedade era composta por indivíduos, a quem eram atribuídos direitos subjetivos que deveriam ser garantidos pela ordem jurídica. Essa maneira de enxergar o fundamento das ordens normativas teve um forte impacto no modo como os juristas passaram a perceber as relações entre pessoas e coisas. ${ }^{21}$

Do ponto de vista da mera construção de categorias doutrinárias, foi no âmbito da teologia moral que novas concepções a respeito das relações jurídicas entre pessoas e coisas começaram a ser inventadas. O domínio, então considerado como inseparável do uso efetivo da coisa, começou a ser entendido, também, como uma disposição subjetiva de ser dono da coisa. Ou seja, o uso não precisava ser fático, material, mas poderia consistir em uma "vontade apropriativa". Assim, a partir da ideia de que o domínio era uma vontade de uma pessoa a ser afirmada sobre uma coisa, começou a ser gestada uma separação entre sujeitos e objetos de direitos. ${ }^{22}$

O homem ${ }^{23}$ passou, então, a ser considerado, por determinados juristas, como um ser livre, autônomo, dotado de vontade. Para que essa vontade fosse satisfeita e a liberdade e autonomia do homem fossem plenamente realizadas, era necessário que sua vontade se

${ }^{20}$ HESPANHA. Como os juristas viam o mundo, pp. 352-360.

${ }^{21}$ Esse processo de criação de um direito de propriedade de caráter subjetivista foi estudado por historiadores das mais diferentes tradições. Há, portanto, uma pluralidade de enfoques e perspectivas para o tratamento desse tema. Alguns exemplos são: BLAUFARB. The Great Demarcation; CLAVERO. "Les domaines de la propriété"; CONGOST. Tierras, leyes, historia; GROSSI. Il dominio e le cose; HALPÉRIN. Histoire du droit des biens; HESPANHA. Como os juristas viam o mundo, pp. 307-319; LUNA. "Property, Dominium, and the Hispanic enlightenment on both sides of the Atlantic in the second half of the eighteenth century", VARELA. Das sesmarias à propriedade moderna.

22 DECOCK. Theologians and Contract Law, pp. 21-104, 352-383; GROSSI. Il dominio e le cose, pp. 281-384; HESPANHA. Como os juristas viam o mundo, pp. 315-317.

23 Ao longo deste trabalho, procuro sempre utilizar a palavra "pessoa", para evitar a redução da espécie humana à metonímia "homem". Porém, nesse caso específico, o sujeito de direitos que estava sendo construído possuía um forte viés de gênero e racial e era identificado com o gênero masculino de origem europeia. Por isso, optei por utilizar a palavra "homem" e não "pessoa". Sobre a construção do sujeito de direitos liberal, ver HUNT. A invenção dos direitos humanos; WELKE. Law and the Borders of Belonging in the Long Nineteenth Century United States. 
projetasse sobre as coisas, apropriando-se delas. O domínio, então, passa a ser visto como um ato de vontade que era, na realidade, a extensão do sujeito sobre o mundo material. Sendo, agora, uma faculdade subjetiva e volitiva, o domínio perdeu, no nível da retórica discursiva, qualquer relação com o uso efetivo das coisas, com sua utilidade e funcionalidade. ${ }^{24}$

O passo seguinte dessa construção de categorias doutrinárias foi identificar o domínio com o direito subjetivo de propriedade e considerar este último como a relação por excelência entre pessoas e coisas. O sistema de direitos reais começou, então, a ser estruturado tomando o direito de propriedade como hierarquicamente superior aos demais direitos sobre as coisas. De acordo com António Manuel Hespanha, nessa nova construção intelectual, o domínio identificado com direito de propriedade tinha três características fundamentais: estava relacionado intimamente com a vontade, era tendencialmente absoluto e era essencialmente privado. ${ }^{25} \mathrm{O}$ autor ressalta, ainda, que o direito de propriedade "não se destinava a garantir a funcionalidade econômica das coisas, não visava refletir, no campo do direito, as utilidades possíveis das coisas, antes possibilitando exercícios afuncionais, como o não cultivo de uma terra ou a destruição de uma coisa". ${ }^{26}$

Pois bem, essa é, em linhas gerais, a história da construção das categorias doutrinárias relacionadas ao direito de propriedade. Nesta tese, pretendo contar essa história de outra maneira. Olhando para o caso brasileiro do século XIX, é possível perceber que as categorias jurídicas do direito comum que regiam as relações entre as pessoas e as coisas adquiriram contornos específicos em território brasileiro. No Atlântico lusófono, havia uma linguagem jurídica compartilhada, mas que ia adquirindo nuances de acordo com o contexto local. No contexto brasileiro, o processo de construção do direito de propriedade foi lento e indeterminado. Lento no sentido de que seu surgimento não aconteceu como um estalo. Concepções sobre o direito de propriedade conviveram com categorias do direito comum e foram, paulatinamente, dotando-as de novos significados. $\mathrm{E}$ indeterminado, porque esse processo não tinha um rumo certo e evidente. Diversas opções estavam em aberto e foram disputadas pelos mais diversos sujeitos históricos. Do modo como esse processo foi tomando forma, uma organização social e jurídica baseada no

${ }^{24}$ GROSSI. Il dominio e le cose, pp. 603-666; HESPANHA. Como os juristas viam o mundo, pp. 316-317.

25 De acordo com Hespanha, é nesse caráter essencialmente privado que reside a construção da separação entre iurisdictio e dominium, operada por certos autores da Escola de Salamanca. HESPANHA. Como os juristas viam o mundo, p. 319.

26 HESPANHA. Como os juristas viam o mundo, pp. 316-318. 
reconhecimento comunitário da titularidade dos bens foi se imiscuindo com formas de organização que privilegiavam relações baseadas na abstração de documentos escritos dotados de determinados requisitos formais. Por fim, argumento que a criação do direito de propriedade liberal criou efeitos de esquecimento, a partir da ilusão de que a origem da propriedade individual pode ser traçada por meio de uma cadeia documental. Esse mito fundacional esconde dois aspectos fundamentais que mostro nesta tese. O primeiro é que, na ordem do direito comum, a ideia de que a titularidade de um bem estaria legitimada por uma cadeia documental é anacrônica. O segundo é que, muitas vezes, a origem da titularidade dos bens era o engodo, a ficção e a violência.

Para descrever esse processo da maneira mais precisa possível, adotei algumas opções terminológicas. "Direito de propriedade" será uma expressão usada para identificar a regulação jurídica das relações entre pessoas e coisas a partir do ponto de vista do direito liberal. Por isso, para evitar confusões, refiro-me às situações de apropriação, uso e conservação de bens por meio da expressão "relações jurídicas entre pessoas e coisas". A palavra "propriedade" será usada, preferencialmente, para designar bens e, quando expressamente indicado no trecho correspondente, para tratar das relações liberais entre pessoas e bens. Como o período analisado é transicional, marcado pelo entranhamento de diferentes concepções normativas, uso, nos casos em que essas duas concepções não se distinguem claramente, a palavra "domínio".

Antes de passar a esses argumento, no entanto, trato de alguns outros aspectos teóricos desta empreitada.

\section{... e a cozinha}

Imagine a vitrine de uma confeitaria. Os doces estão lá: organizados, coloridos, bonitos. Enchem os olhos. Ao olhar essa vitrine, frequentemente, não pensamos em todo o processo que levou à sua confecção. Não nos lembramos que existe uma cozinha. E que é nessa cozinha que aqueles doces tão bonitos são produzidos cotidianamente, a partir do trabalho e da agência das pessoas que estão ali "escondidas", que são invisíveis aos olhos do cliente que se deslumbra com o produto final exposto através do vidro.

As categorias jurídicas nos são apresentadas assim: como doces em vitrines. Organizadas, perfeitas, acabadas. Os textos jurídicos costumam ostentá-las solenemente 
como um produto já finalizado, como partes de um sistema coerente e organizado de normas. As categorias jurídicas, no entanto, não existem, no mundo, dessa forma. Houve, na cozinha, um processo conturbado, conflituoso, contingente, de sua produção. Esta pesquisa se propõe a olhar para a cozinha do direito, para o processo de construção cotidiana das categorias jurídicas que estruturavam as relações entre pessoas e coisas, no Brasil do século XIX.

Para realizar essa análise, parto de alguns pressupostos teóricos. O primeiro é o de que direito e sociedade são mutuamente constitutivos. Em outras palavras, a divisão entre direito e realidade social é artificial. É muito comum, entre pesquisadores, o pressuposto de que "o jurídico" e "o social” são duas "esferas" distintas, apesar de relacionadas entre si. As pesquisas que assumem essa separação entre direito e sociedade tendem a ver o direito como uma construção erudita - empreendida em lugares solenes - que está em constante tensão com uma prática social, com "costumes", com o "real". Também é comum que pesquisadores que assumem esse pressuposto trabalhem com categorias - como, por exemplo, "posse" - como se elas fossem completamente independentes do direito, sendo exclusivamente fruto das relações sociais ou de uma suposta "prática costumeira". No entanto, se considerarmos a divisão entre direito e sociedade como artificial, perceberemos que basicamente qualquer instituição social - propriedade, agregado, posse, mulher, escravo, etc. - é constituída, em certa medida, por relações jurídicas. O direito atua, portanto, constituindo os termos em que se darão as relações sociais. Essa perspectiva permite enxergar o direito de uma maneira mais ampla, não restrita apenas a normas escritas emanadas por instâncias solenes de produção. ${ }^{27}$

Como direito e sociedade são mutuamente constitutivos, o direito conforma as relações sociais mas é, também, conformado por elas. O direito, suas categorias, suas instituições e seus procedimentos são produtos de conflitos sociais. Os significados das categorias e normas jurídicas são constantemente disputados, entre diferentes sujeitos históricos, sejam eles as classes dominantes ou grupos subalternos. É nesse sentido que se pode afirmar que o direito é uma arena de conflitos. Daí que ele é uma ordem de construções normativas conflitivas e, frequentemente, incoerentes entre si; apesar de ser constantemente apresentado como um sistema coerente. O caráter conflitivo do direito é o

${ }^{27}$ GORDON. "Critical Legal Histories". 
que permite a disputa entre significados alternativos a serem dados a suas normas e categorias. ${ }^{28}$

Apesar de serem produtos de conflitos, o direito e as categorias jurídicas que o estruturam não necessariamente respondem a qualquer realinhamento das forças sociais. Eles tendem a funcionar de maneira "relativamente autônoma", inclusive, moldando os termos dos interesses dos grupos sociais. Nesse sentido, não é possível analisar as relações jurídicas apenas a partir de referenciais externos, sejam eles a política, a economia ou algum outro fator. A análise deve levar em conta, além desses referenciais externos ao direito, a lógica interna da arquitetura de ordens normativas e o modo como essa lógica foi forjada a partir de relações sociais. A linguagem por meio da qual o direito opera é o que garante o seu funcionamento como uma arena de lutas e não apenas como instrumento de exploração produzido pelas classes dominantes. É por meio da manipulação das possibilidades abertas por essa linguagem que grupos subalternos conseguem imprimir significados às categorias jurídicas. ${ }^{29}$

É a partir dessas perspectivas que analisarei as relações jurídicas entre pessoas e coisas no Brasil oitocentista. Como já mencionei, a "Era das Revoluções" também foi marcada pela disputa de novas concepções de como essas relações deveriam ser estruturadas, partindo de pressupostos diversos dos que estavam na base do direito comum. Foi nesse período que um "direito de propriedade" foi sendo construído. Essa construção foi conflitiva, contingente, diversas possibilidades estavam abertas, diferentes caminhos poderiam ter sido adotados. As condições da vida social e, portanto, do direito, são radicalmente indeterminadas. O mesmo corpo normativo pode levar a resultados diferentes, quando aplicado a determinados contextos. Por exemplo, o corpo normativo do direito comum, compartilhado na experiência jurídica do Atlântico lusófono, adquiria significados específicos quando confrontado com situações concretas na Europa, na África ou na América. Da mesma maneira, diversos projetos de construção de "direito de propriedade" concorriam entre si no período analisado. Por isso, é necessário estar atento às condições de realização das relações jurídicas entre as pessoas e as coisas. ${ }^{30}$

${ }^{28}$ GORDON. "Critical Legal Histories”. THOMPSON. Whigs and Hunters, pp. 258-269.

${ }^{29}$ GORDON. "Critical Legal Histories". THOMPSON. Whigs and Hunters, pp. 258-269.

${ }^{30}$ CONGOST. Tierras, leyes, historia, pp. 11-41; GORDON. "Critical Legal Histories"; BARBOSA. "Indeterminação do constitucionalismo imperial luso-brasileiro e o processo de independência do Brasil" 
Além de olhar o direito pela cozinha, de tomar direito e sociedade como mutuamente constitutivos e de ressaltar suas origens conflitivas, esta pesquisa parte do pressuposto de que as categorias jurídicas que estruturam as relações entre pessoas e coisas não são, propriamente, "nacionais". ${ }^{31}$ As complexidades de processos de grande escala como esse são melhor apreendidas quando observadas em suas dinâmicas de pequena escala. Há processos históricos que só se tornam "visíveis" quando olhados muito de perto, quando analisada a dinâmica cotidiana e conflituosa das relações entre escravos, senhores, mulheres, agregados, indígenas, libertos, juristas, agentes estatais, etc. Como argumentam Jean Hébrard e Rebecca Scott, “não há nada de 'micro' no mundo atlântico do século XIX, mas mesmo nesse quadro tão amplo, a análise mais profunda pode surgir da intensa atenção ao particular". 32

Esta pesquisa conjuga, então, duas perspectivas. Por um lado, considero que uma dimensão atlântica é importante para compreender o fenômeno histórico do direito comum. É simplista considerar que o direito comum foi uma construção europeia transplantada para os territórios coloniais e que sobreviveu, em certos aspectos, à emergência dos Estados nacionais. Ao contrário, o Atlântico lusófono foi um ambiente jurídico construído por meio da circulação cotidiana de pessoas, ideias e práticas jurídicas. Nele, o direito comum atuava como uma arquitetura normativa compartilhada, cujas categorias adquiriam significados específicos em contextos locais e em face de conflitos concretos. Nessa dinâmica, o caminho não era de mão única, da Europa para a América e para a África, mas circular. O direito ia e voltava nos navios que cruzavam o oceano e, nesse movimento, significados adquiridos em contextos específicos acabavam influenciando a configuração que essas categorias adquiriam em outras regiões. Essa dinâmica de construção de categorias e atribuição de significados é mais visível adotando a segunda perspectiva desta pesquisa: uma história social do direito que privilegia uma análise empírica de nível micro, focando em conflitos localizados que, em seu conjunto, ajudam a elucidar processos de escala mais ampla. Uma análise feita em uma escala menor também permite identificar os mecanismos de construção de assimetrias envolvidos nesses processos.

${ }^{31}$ DUVE. "European Legal History" e HERZOG. Frontiers of Possession, pp. 1-15.

${ }^{32}$ FERREIRA. Cross-Cultural Exchange in the Atlantic World, pp. 1-19; GALEANO. Criminosos viajantes, pp. 13-40; HÉBRARD; SCOTT. Provas de liberdade, pp. 15-19; HERZOG. Frontiers of Possession, pp. 115; MAMIGONIAN. "José Majojo e Francisco Moçambique, marinheiros das rotas atlânticas"; PREMO. The Enlightenment on Trial, pp. 1-25; PUTNAM. "To Study the Fragments/Whole"; SCOTT. "Small-Scale Dynamics of Large-Scale Processes"; SCOTT. "Slavery and the Law in Atlantic Perspective". 
Por essas razões, analiso o caso brasileiro, aproximadamente, entre 1835 e $1889 . \mathrm{Na}$ análise da documentação, optei por evidenciar conexões e experiências compartilhadas entre os casos analisados e um contexto Atlântico mais amplo, que engloba, na medida do possível, experiências latino-americanas e africanas. O tempo e o esforço que uma pesquisa empírica em outras regiões demandaria estão além dos limites desta pesquisa. Por isso, procurei, ao tratar do contexto brasileiro, evidenciar os trânsitos e movimentos dos sujeitos históricos envolvidos nos processos analisados, além das similaridades e diferenças que marcavam outros contextos nacionais do mundo atlântico.

Esta pesquisa está baseada, sobretudo, na análise de processos judiciais. Em razão de todos os pressupostos teórico-metodológicos explicitados, considero que esse tipo de fonte é bastante elucidativo da construção social cotidiana das categorias jurídicas que estruturavam as relações entre pessoas e coisas. Os conflitos judiciais nos permitem identificar quais opções normativas eram disputadas e mobilizadas pelos sujeitos históricos. Por meio deles, é possível observar o processo de produção de normatividades e de categorias jurídicas. Nos processos judiciais, o local e o atlântico se articulam de maneira complexa. Além disso, processos judiciais deixam entrever como entendimentos vernaculares das normatividades disponíveis interagem e tensionam com interpretações das categorias jurídicas produzidas em lugares solenes. ${ }^{33} \mathrm{~A}$ narrativa dos processos não é anedótica ou retórica. É uma opção analítica que tem como objetivo identificar as estratégias e as particularidades dos diferentes discursos jurídicos mobilizados pelos sujeitos históricos que se envolveram nesses conflitos judiciais. Nesse sentido, cada um dos casos analisados não é mera ilustração do processo de construção do direito de propriedade, mas elementos constitutivos desse processo. ${ }^{34}$

Para esta pesquisa, analisei um total de 74 processos ajuizados perante o Tribunal da Relação do Rio de Janeiro (TRRJ), entre 1834 e 1887, disponíveis no Arquivo Nacional do Rio de Janeiro. Os processos consultados foram selecionados de acordo com o seguinte procedimento. Optei por analisar os documentos que integram a série "apelação cível", do fundo "Relação do Rio de Janeiro". A partir das definições disponibilizadas pelo Arquivo Nacional, na aba "vocabulário", da Base de Dados Acervo Judiciário, selecionei as

${ }^{33}$ FARGE. O sabor do arquivo; DUVE. "Was ist 'Multinormativität'?"; HERZOG. Upholding Justice, pp. 118; HERZOG. Frontiers of Possession, pp. 1-15; PREMO. Enlightenment on Trial, pp. 1-25; ZEMON DAVIS. O retorno de Martin Guerre; e ZEMON DAVIS. "On the Lame".

${ }^{34}$ SCOTT. "Small-Scale Dynamics of Large-Scale Processes"; SCOTT. "Slavery and the Law in Atlantic Perspective". 
seguintes palavras-chave: “alforria”, “demarcação", “esbulho possessório”, “escravo”, "interdito possessório", "liberdade", "manutenção de liberdade", "manutenção de posse", "nunciação de obra nova", "posse", "prescrição", "propriedade rural”, "reintegração de posse", "sesmaria", "tráfico de escravo" e "usufruto". Fiz, então, uma seleção aleatória de dois processos sobre terras e dois sobre escravos por ano. Nas ações sobre escravos, selecionei uma relativa à definição de estatuto jurídico e outra que discutisse a propriedade, entre dois senhores, sobre um escravo. No entanto, em visita ao Arquivo Nacional, diversas das ações selecionadas não estavam disponíveis para consulta. Os funcionários, então, disponibilizaram outros processos, também escolhidos, por eles, de maneira aleatória. Dentre as ações que pude consultar, poucas discutiam a propriedade sobre um escravo, entre dois senhores. Então, o pesquisador Clemente Penna, gentilmente, cedeu-me algumas das ações que, em suas pesquisa, ele havia recolhido sobre esse tema. Algumas dessas ações não integram a série "apelação cível" nem o fundo "Relação do Rio de Janeiro". Ao fim, terminei por analisar uma série de processos judiciais discutindo a a titularidade de terras e escravos selecionados aleatoriamente, tanto pelo procedimento de seleção inicial quanto pela sua disponibilidade durante o período em que realizei a pesquisa. A lista completa desses processos pode ser encontrada nas referências bibliográficas deste trabalho.

Construí os argumentos deste trabalho pela análise conjunta de todos esses processos. Contudo, para efeitos de exposição dos argumentos, elegi três casos, um a cada capítulo, para um relato mais detido que me permitisse estruturar a linha de argumentação. Os demais processos foram usados incidentalmente ao longo da exposição, para desenvolver determinados argumentos e mostrar aspectos específicos das relações sociais e jurídicas que se estabeleceram entre pessoas e coisas no Brasil oitocentista. 


\section{CONCLUSÃO}

"A posse é aquele direito pelo qual alguém tem um verdadeiro poder sobre uma coisa corpórea, designando a detenção da coisa corpórea a partir da imposição dos pés”.

Criada no âmbito do direito comum, a posse cruzou o oceano e se constituiu como a principal categoria jurídica reguladora das relações entre pessoas e coisas no Atlântico lusófono. Nessas viagens, a posse foi sendo ressignificada a partir de conflitos e peculiaridades locais. Na América portuguesa, a posse desembarcou em uma sociedade escravista e patriarcal. Os sentidos que ela, então, adquiriu, estavam intrinsecamente vinculados às estruturas de uma sociedade regida pela lógica do favor e da produção de dependentes.

A posse garantia que as comunidades tivessem um papel central nos processos de construção e reconhecimento de direitos sobre as coisas. À publicidade, um de seus elementos essenciais, correspondia o reconhecimento social. O reconhecimento social era decisivo na maneira como as relações entre coisas e pessoas se organizavam. Nos processos judiciais, ele impunha os conhecimentos convencionais da comunidade à resolução de conflitos. As testemunhas apareciam como uma espécie de representantes da comunidade local e forneciam, através de suas experiências, os meios de prova com maior capacidade de decidir um litígio envolvendo os direitos sobre um bem.

Mesmo com os debates sobre a construção do direito de propriedade liberal que já circulavam no Brasil oitocentista, a posse continuou mantendo um papel de destaque na estruturação das relações entre pessoas e coisas até, aproximadamente, a década de 1870. Por não ter rumo previamente definido, o processo de construção do direito de propriedade abria possibilidades de disputa aos mais diversos sujeitos históricos. Assim, os processos judiciais do período eram marcados por debates a respeito de quais seriam os títulos aptos a constituir e comprovar domínio sobre os bens, quem eram os sujeitos legitimados a produzi-los e como eles deveriam ser feitos.

Nesse contexto de indeterminação, os sujeitos tinham uma ampla margem de atuação. E aproveitavam-na, produzindo documentos informados, muitas vezes, por 
entendimentos compartilhados a respeito do que seria um título apto a comprovar o domínio. Em muitos casos, era a própria posse ou o reconhecimento social que garantiam a força desses documentos em disputas judiciais. Se, de um lado, alguns documentos foram se firmando como capazes de provar direitos sobre bens; de outro, certos documentos eram sistematicamente desconsiderados, não por suas características intrínsecas, mas em razão das pessoas que os produziam. As mulheres casadas eram excluídas, pela violência, pela fraude e pelo direito, da possibilidade de produzir documentos que lhes garantissem direitos sobre bens.

É verdade que, assim como evidencia a definição de Amaral, a posse era, majoritariamente, uma relação muito concreta, de pés no chão. As relações entre pessoas e coisas estruturadas a partir da arquitetura jurídica do direito comum eram dotadas de uma concretude maior do que a que foram adquirindo com o processo de construção do direito de propriedade. Nesse processo, elevou-se o nível de abstração dessas relações, por meio da marginalização do papel das comunidades, concentrando a via de legitimação dessas relações, cada vez mais, em saberes especializados e burocráticos.

Mas não podemos nos iludir com um suposto caráter idílico da posse. A teoria possessória também tinha muito de ficção. Como mostrei, ela permitia a reprodução de estruturas de dependência, na medida em que foram sendo construídas interpretações que legitimavam os atos possessórios de uns grupos e deslegitimavam os de outros, como os dos índios e os dos agregados. Mais do que isso, no contexto brasileiro, o trabalho de escravos e agregados garantia a expansão das terras dos "senhores" que não trabalhavam, garantia, enfim, o contínuo aumento de seu domínio por meio do trabalho alheio, que era desconsiderado como ato possessório.

Uma das consequências da regulação operada pelo direito comum era a conservação do status quo, no que dizia respeito às relações entre pessoas e coisas. Esse traço conservador, no entanto, poderia gerar o apagamento de aquisições de domínio baseadas na força, no artifício e na ilegalidade. A posse era um meio jurídico legítimo para “regularizar" essas aquisições que, à primeira vista, poderiam parecer irregulares, como por exemplo, os casos das sesmarias em comisso. Processo similar acontecia nos casos de escravização ilegal. Apesar de expressamente proibida a aquisição de alguém por posse, os processos analisados deixam entrever que, na prática cotidiana, a posse, sim, atuava legitimando situações de domínio ilegal adquirido sobre escravos. 
O Estado brasileiro teve protagonismo nesses processos de legitimação de aquisições ilegais. No momento em que o governo começou a querer impor determinados padrões de confecção e prova de direitos de domínio - por meio, principalmente, de escrituras públicas e matrículas de escravos -, houve negociações com as classes senhoriais no sentido de não viesse a ser requerido, nos processos de registro, prova de aquisição do domínio. Esse pacto entre Estado e senhores garantiu a regularização de grande quantidade de propriedade escrava e fundiária adquirida ilegalmente. Isso sem mencionar os casos de corrupção e omissão de agentes estatais na fiscalização da aquisição ilegal de propriedade escrava.

O processo de construção do direito de propriedade, no Brasil oitocentista, foi lento e marcado por idas e vindas. O direito de propriedade liberal não foi implementado no país de uma vez por todas. Ele tampouco era incompatível com os institutos do direito comum. Pelo contrário, parte de seu sucesso se deveu a sua capacidade de aproveitar esses institutos, dotando-os de novos significados, como no caso, por exemplo, dos filtros produtores de títulos que eram os processos de demarcação.

A análise de processos judiciais permite acessar o processo de construção do direito de propriedade a partir de uma escala micro. Dessa perspectiva, observa-se que, na origem do direito de propriedade, destacava-se, de uma parte, a atualização de sistemas de exclusão anteriores e, de outra, a legitimação de fraudes e violências, muitas vezes, com a participação ativa do Estado. Visto da vitrine, o direito de propriedade apresenta uma versão de sua própria história, evocando, como seu fundamento originário, cadeias documentais cuja extensão seria proporcional a sua legitimidade. Porém, se olharmos para a cozinha, veremos seus rastros no direito comum, a legitimidade advinda de atos possessórios e do reconhecimento social, os documentos produzidos pela violência e pelo artifício, as fraudes, as ilegalidades. 


\section{REFERÊNCIAS BIBLIOGRÁFICAS}

\section{Fontes primárias}

Arquivo Nacional do Rio de Janeiro

Processo número 2, fundo 84 Relação do Rio de Janeiro, série apelação cível, código de referência 84.0.ACI.00136, apelada Francisca, apelante João do Carmo e Silva, ano inicial 1867, ano final 1871, caixa 3.688, local Itajubá, microfilme AN_077_2006.

Processo número 7, fundo 84 Relação do Rio de Janeiro, série apelação cível, código de referência 84.0.ACI.00104, apelante Maria, apelante Isabel, ano inicial 1863, ano final 1864, caixa 3.690, local Angra dos Reis, microfilme AN_067_2006.

Processo número 11, fundo 84 Relação do Rio de Janeiro, série apelação cível, código de referência 84.0.ACI.00007, apelante Joana Maria da Conceição, apelado João, ano inicial 1835, ano final 1838, caixa 3.696, local São Gonçalo, microfilme AN_035_2006.

Processo número 29, fundo 84 Relação do Rio de Janeiro, série apelação cível, código de referência 84.0.ACI.08931, apelante Francisco do Carmo Fróes, apelante Henrique José da Silva Barbosa, apelado Jose Hipolito da Silva, ano inicial 1837, ano final 1840, caixa 273, local Barra Mansa.

Processo número 36, fundo 84 Relação do Rio de Janeiro, série apelação cível, código de referência 84.0.ACI.00305, apelante José Florêncio de Melo, apelada Teodora, falecido Manuel Antônio de Melo, ano inicial 1875, ano final 1877, maço 2.244, local Vassouras.

Processo número 42, fundo 84 Relação do Rio de Janeiro, série apelação cível, código de referência 84.0.ACI.09655, apelante José Álvares, apelado Joaquim da Silva Ramos Arouca, ano inicial 1869, ano final 1871, caixa 529, galeria C, local Rio de Janeiro.

Processo número 59, fundo 84 Relação do Rio de Janeiro, série apelação cível, código de referência 84.0.ACI.09683, apelante José da Silva Carvalho, apelado Domingos José Marques Viana, ano inicial 1867, ano final 1868, caixa 530, galeria C, local Rio de Janeiro. 
Processo número 62, fundo 84 Relação do Rio de Janeiro, série apelação cível, código de referência 84.0.ACI.03159, apelante João Evangelista Teixeira Leite, apelada Rosa Teixeira Pompeia, ano inicial 1885, ano final 1888, maço 129, galeria C, local Rio de Janeiro.

Processo número 103, fundo 84 Relação do Rio de Janeiro, série apelação cível, código de referência 84.0.ACI.09468, apelante Francisco Alves Ferreira do Amaral, apelado José Pires de Almeida, ano inicial 1837, ano final 1842, caixa 513, galeria C, local São Paulo.

Processo número 159, fundo 84 Relação do Rio de Janeiro, série apelação cível, código de referência 84.0.ACI.00321, apelante o Juízo, apelado Manuel José da Cunha Osório, apelante Maria, ano inicial 1882, ano final 1886, maço 10, galeria C, local Rio de Janeiro.

Processo número 165, fundo 84 Relação do Rio de Janeiro, série apelação cível, código de referência 84.0.ACI.00926, apelante Manuel, apelado Manuel Paulo de Oliveira, ano inicial 1877, ano final 1880, maço 10, galeria C, local Rio de Janeiro.

Processo número 208, fundo 84 Relação do Rio de Janeiro, série apelação cível, código de referência 84.0.ACI.00296, apelada Maria Esteves, apelante Mateus (escravo), ano inicial 1883, ano final 1884, caixa 1.825, galeria A, local Vila da Barra de São Matheus - Espírito Santo.

Processo número 223, fundo 84 Relação do Rio de Janeiro, série apelação cível, código de referência 84.0.ACI.09968, apelante João Pereira de Magalhães Bastos, apelado Francisco José Correia, ano inicial 1855, ano final 1858, caixa 538, galeria C, local Niterói.

Processo número 239, fundo 84 Relação do Rio de Janeiro, série apelação cível, código de referência 84.0.ACI.10010, apelante Antônio Ferreira Pinto, apelado Joaquim José de Paiva, ano inicial 1877, ano final 1879, caixa 539, galeria C, local Campos.

Processo número 249, fundo 84 Relação do Rio de Janeiro, série apelação cível, código de referência 84.0.ACI.00215, apelante o juízo, apelado Antonio Pinto Loureiro, apelante Marcelino, ano inicial 1887, ano final 1888, caixa 2.336, galeria A, local Serra.

Processo número 284, fundo 84 Relação do Rio de Janeiro, série apelação cível, código de referência 84.0.ACI.00836, apelante José Pereira de Barcelos, apelado Benedito, 
falecida Catarina Pereira de Jesus, ano inicial 1879, ano final 1884, maço 16, galeria $\mathrm{C}$, local Serra.

Processo número 465, fundo 84 Relação do Rio de Janeiro, série apelação cível, código de referência 84.0.ACI.05524, apelante Feliciano, apelado Manuel Gomes de Sousa, ano inicial 1881, ano final 1882, maço 2247, local Campos dos Goytacazes.

Processo número 716, fundo 84 Relação do Rio de Janeiro, série apelação cível, embargada Maria Madalena da Cunha, embargante Antônio Rodrigues de Amorim, ano inicial 1851, ano final 1852, caixa 41, galeria C.

Processo número 843, fundo 84 Relação do Rio de Janeiro, série apelação cível, código de referência 84.0.ACI.00008, apelante Antônio, apelado Inácio Rodrigues dos Santos, ano inicial 1835, ano final 1840, caixa 3.683, local Magé, microfilme AN_035_2006.

Processo número 866, fundo 84 Relação do Rio de Janeiro, série apelação cível, código de referência 84.0.ACI.00014, apelante Felisminda, apelado Francisco Machado, ano inicial 1836, ano final 1839, caixa 3.685, local Rio de Janeiro, microfilme AN_037_2006.

Processo número 916, fundo ZU Juízo municipal da $1^{\text {a }}$ vara do Rio de Janeiro, justificado Tiberio Tomas de Aquino, justificante Domingos José da Costa, ano inicial 1865, ano final 1865, maço 110.

Processo número 1.110, fundo 84 Relação do Rio de Janeiro, série habeas corpus, impetrante João Andrade Pessoa, paciente Teresa, ano inicial 1883, ano final 1883, maço 7, galeria F, local Rio de Janeiro.

Processo número 1.190, fundo 84 Relação do Rio de Janeiro, série apelação cível, código de referência 84.0.ACI.00025, apelante Florentino, apelado Antônio Manuel Leite, ano inicial 1841, ano final 1844, caixa 3.687, local Santo Antônio de Sá, microfilme AN_040_2006.

Processo número 1.222, fundo 84 Relação do Rio de Janeiro, série apelação cível, código de referência 84.0.ACI.00015, apelada Jacinta, ano inicial 1839, ano final 1844, caixa 3.690, local Cabo Frio, microfilme AN_037_2006.

Processo número 1.295, fundo 84 Relação do Rio de Janeiro, série apelação cível, código de referência 84.0.ACI.10270, apelante Joaquina Maria da Trindade, apelado 
Herdeiros de João José de Campos, ano inicial 1855, ano final 1864, caixa 596, galeria $\mathrm{C}$, local Vila de Limeira.

Processo número 1.353, fundo 84 Relação do Rio de Janeiro, série recurso criminal, apelante o Juízo, apelado Agostinho Leitão de Almeida, ano inicial 1853, ano final 1853, caixa 144, galeria C, local Desterro.

Processo número 1.385, fundo 84 Relação do Rio de Janeiro, série apelação cível, código de referência 84.0.ACI.10582, apelante Tristão José de Oliveira, apelado Joaquim Tomás da Silva Prado, ano inicial 1853, ano final 1861, caixa 600, galeria C, local Cruz Alta.

Processo número 1.669, fundo 84 Relação do Rio de Janeiro, série apelação cível, código de referência 84.0.ACI.00035, apelante Francisco Oliveira Martins, apelado José, ano inicial 1845, ano final 1850, caixa 3.688, local Santa Catarina, microfilme AN_045_2006.

Processo número 1.742, fundo 84 Relação do Rio de Janeiro, série apelação cível, código de referência 84.0.ACI.00661, apelado João Pedro de Andrade, apelante Rita e seus filhos, falecida Matildes Ferreira Toledo, ano inicial 1880, ano final 1881, maço 216, galeria C, local Barra Mansa.

Processo número 1.811, fundo 84 Relação do Rio de Janeiro, série apelação criminal, apelante Promotor Público da Cidade de Desterro, apelado Domingos Marinho, ano inicial 1844, ano final 1846, maço 98, galeria C, local Desterro.

Processo número 1.854, fundo 84 Relação do Rio de Janeiro, série apelação cível, código de referência 84.0.ACI.00082, apelante Firmino, apelado Manuel Antônio Ferreira, ano inicial 1859, ano final 1859, caixa 3.684, local Rio de Janeiro, AN_060_2006.

Processo número 2.603, fundo 84 Relação do Rio de Janeiro, série apelação cível, código de referência 84.0.ACI.03901, apelante Dionísia da França Dinheiro, apelado João Antônio de Melo, ano inicial 1869, ano final 1872, maço 234, local Antonina.

Processo número 2.837, fundo 84 Relação do Rio de Janeiro, série apelação cível, código de referência 84.0.ACI.04006, apelante Joaquim José de Sousa Breves, apelado Antônio Rodrigues de Sousa, falecido Luciano da Silva Coutinho, ano inicial 1857, ano final 1861, maço 252, galeria C, local São José do Príncipe. 
Processo número 3.122, fundo 84 Relação do Rio de Janeiro, série apelação cível, código de referência 84.0.ACI.00039, apelado Manuel, ano inicial 1847, ano final 1851, caixa 3.687, local São João del Rei, microfilme AN_046_2006.

Processo número 3.130, fundo ZV Juízo Municipal da $2^{\mathrm{a}}$ Vara do Rio de Janeiro, réu José Alves Maciel e Cunha, autor Antônio Martins de Lima, ano inicial 1851, ano final 1851, maço 846, galeria A.

Processo número 3.204, fundo 84 Relação do Rio de Janeiro, série apelação cível, código de referência 84.0.ACI.10329, apelante Mariana Rosa de Jesus, apelado Amaro Pacheco Sabrosa, ano inicial 1861, ano final 1865, caixa 1.655, galeria A, local Cabo Frio.

Processo número 3.816, fundo 84 Relação do Rio de Janeiro, série agravo, agravante Joaquim José Gonçalves Morais, agravado Joaquim José de Sousa Borges, Manuel Ferreira do Prado, ano inicial 1879, ano final 1879, caixa 1.690, galeria A, local São João do Príncipe.

Processo número 4.593, fundo 84 Relação do Rio de Janeiro, série apelação cível, código de referência 84.0.ACI.08418, apelado Francisco Feliciano dos Santos, apelante Clemente Francisco Maciel, ano inicial 1871, ano final 1875, caixa 221, galeria C, local Minas Novas.

Processo número 4.649, fundo 84 Relação do Rio de Janeiro, série apelação cível, código de referência 84.0.ACI.08643, apelante Francisco de Sousa Vieira, apelado Francisco Gomes Coelho, ano inicial 1873, ano final 1875, caixa 410, galeria C, local Vassouras.

Processo número 4.679, fundo 84 Relação do Rio de Janeiro, suplicante Antônio Feliz da Silva, suplicado José Antônio de Azevedo Castro, ano inicial 1849, ano final 1850, caixa 1.719 , galeria A.

Processo número 4.916, fundo 84 Relação do Rio de Janeiro, série apelação cível, código de referência 84.0.ACI.06943, apelante Teotonio Ferreira de Carvalho, apelado Casimiro José da Costa, ano inicial 1845, ano final 1854, caixa 241, galeria C.

Processo número 5.142, fundo 84 Relação do Rio de Janeiro, série apelação cível, código de referência 84.0.ACI.07231, apelante Pinto Júnior \& Cia, apelada a Ilustríssima Câmara Municipal da Corte, ano inicial 1881, ano final 1882, caixa 254, galeria C, local Rio de Janeiro. 
Processo número 5.381, fundo 84 Relação do Rio de Janeiro, série apelação cível, código de referência 84.0.ACI.05012, apelante Silvestre Coelho de Oliveira, apelado Manuel Pereira Baia, ano inicial 1863, ano final 1870, maço 49, local São Manoel do Pomba.

Processo número 5.634, fundo 84 Relação do Rio de Janeiro, série apelação cível, código de referência 84.0.ACI.02527, apelante José Dias, apelante José Soares, apelado Manuel Pereira da Silva, ano inicial 1841, ano final 1844, maço 72, local São João da Barra.

Processo número 5.854, fundo 84 Relação do Rio de Janeiro, série apelação cível, código de referência 84.0.ACI.07711, apelado Francisco Rodrigues César, apelante Eduardo José Pedroso, ano inicial 1867, ano final 1873, caixa 295, galeria C, local São Paulo.

Processo número 6.039, fundo 84 Relação do Rio de Janeiro, série apelação cível, código de referência 84.0.ACI.00044, apelante Maria, apelado Catarina Luísa da Conceição, ano inicial 1849, ano final 1854, caixa 3.689, local Vila do Rio Bonito, microfilme AN_047_2006.

Processo número 6.487, fundo 84 Relação do Rio de Janeiro, série apelação cível, código de referência 84.0.ACI.07794, apelante Fernando José de Sampaio, apelado Antônio Joaquim Mendes, ano inicial 1859, ano final 1864, caixa 336, galeria C, local Parati.

Processo número 6.510, fundo 84 Relação do Rio de Janeiro, série apelação cível, código de referência 84.0.ACI.03423, apelante Bernardo da Costa Rodrigues, apelada Maria Amélia França, ano inicial 1883, ano final 1885, maço 131, local Resende.

Processo número 6.539, fundo 84 Relação do Rio de Janeiro, série apelação cível, código de referência 84.0.ACI.07881, apelante Fidélis dos Santos Amaral, apelado Francisco Teixeira da Silva, ano inicial 1838, ano final 1839, caixa 339, galeria C, local Itaboraí.

Processo número 6.588, fundo 84 Relação do Rio de Janeiro, série apelação cível, código de referência 84.0.ACI.07816, apelante Francisco Xavier Cunha, apelado Inácio José Dias, ano inicial 1835, ano final 1838, caixa 342, galeria C, local Resende.

Processo número 6.839, fundo 84 Relação do Rio de Janeiro, série apelação cível, código de referência 84.0.ACI.08077, apelante Ana Maria Pereira, apelada Francisca de 
Oliveira Miranda, ano inicial 1847 , ano final 1852 , caixa 358 , galeria $\mathrm{C}$, local Paranaguá.

Processo número 6.873, fundo 84 Relação do Rio de Janeiro, série apelação cível, código de referência 84.0.ACI.04593, apelante Manuel dos Santos Coutinho, apelado Francisco Rodrigues de Amorim, ano inicial 1865, ano final 1865, maço 157, local Espírito Santo.

Processo número 6.884, fundo 84 Relação do Rio de Janeiro, série apelação cível, notificante Maria Madalena de Macedo, notificada Ana Maria da Conceição, ano inicial 1863, ano final 1864, maço 157, local Rio de Janeiro.

Processo número 6.935, fundo 84 Relação do Rio de Janeiro, série apelação cível, apelante Miguel José Miler, apelado Rafael Joaquim de Andrade, ano inicial 1875, maço 160.

Processo número 7.434, fundo 84 Relação do Rio de Janeiro, série apelação cível, código de referência 84.0.ACI.10274, apelante Francisco Gomes da Silva Figueira, apelado Felismino Gomes de Aguiar, ano inicial 1877, ano final 1881, caixa 400, galeria C, local Paraíba do Sul.

Processo número 7.675, fundo 84 Relação do Rio de Janeiro, série apelação cível, código de referência 84.0.ACI.01619, apelante José Pereira de Almeida, apelado Ricardo Lustosa, ano inicial 1843, ano final 1848, maço 11, local Curitiba.

Processo número 7.901, fundo Relação do Rio de Janeiro, série apelação cível, código de referência 84.0.ACI.10662, apelante Serafim Gonçalves de Macedo, apelado Joaquim Gomes Lagoeiro, ano inicial 1857, ano final 1867, maço 6, local Vila Januária.

Processo número 10.110, fundo 84 Relação do Rio de Janeiro, série apelação cível, código de referência 84.0.ACI.00103, apelada Mariana, ano inicial 1863, ano final 1865, caixa 3.695, local Lorena, microfilme AN_067_2006.

Processo número 11.020, fundo 84 Relação do Rio de Janeiro, série apelação cível, código de referência 84.0.ACI.00091, apelante José Rufino dos Santos Meneses, apelada Maria das Mercês, ano inicial 1861, ano final 1865, caixa 3.696, local São Gabriel, microfilme AN_062_2006.

Processo número 11.051, fundo 84 Relação do Rio de Janeiro, série apelação cível, código de referência 84.0.ACI.00124, apelante Adão, apelado Desidério Francisco de 
Freitas, ano inicial 1865, ano final 1866, caixa 3.685, local Poços de Caldas, microfilme AN_074_2006.

Processo número 11.117, fundo 84 Relação do Rio de Janeiro, série apelação cível, código de referência 84.0.ACI.00203, apelante Leonardo Jorge de Campos, apelada Rita, ano inicial 1863, ano final 1864, caixa 3.681, local Desterro, microfilme AN_096_2006.

Processo número 11.232, fundo 84 Relação do Rio de Janeiro, série apelação cível, código de referência 84.0.ACI.00093, apelante Ana, apelado José Delfino da Silva, ano inicial 1861, ano final 1867, caixa 3.684, local Itabira, microfilme AN_063_2006.

Processo número 11.321, fundo 84 Relação do Rio de Janeiro, série apelação cível, código de referência 84.0.ACI.00123, apelante Angélica, apelante Antônio de Melo, ano inicial 1865, ano final 1871, caixa 3.690, local Antonina, microfilme AN_074_2006.

Processo número 11.339, fundo 84 Relação do Rio de Janeiro, série apelação cível, código de referência 84.0.ACI.00105, apelante Gabriela, apelado Arman Habiaga, ano inicial 1863, ano final 1867, caixa 3.684, local Vila de Caçapava, microfilme AN_067_2006.

Processo número 12.098, fundo 84 Relação do Rio de Janeiro, série apelação cível, código de referência 84.0.ACI.00137, apelante Bento, apelado Joaquim Maria Rosa, ano inicial 1868, ano final 1869, caixa 3.694, local Rio de Janeiro, microfilme AN_077_2006.

Processo número 12.888, fundo 84 Relação do Rio de Janeiro, série apelação cível, código de referência 84.0.ACI.00158, apelante Carolina, apelado Felicíssimo Antônio Gomes, ano inicial 1869, ano final 1870, caixa 3.682, local Rio de Janeiro, microfilme AN_084_2006.

Processo número 13.205, fundo 84 Relação do Rio de Janeiro, série apelação cível, código de referência 84.0.ACI.00154, apelante Ricardo, apelado Manuel Alves dos Santos, ano inicial 1869, ano final 1871, caixa 3.689, local Rio de Janeiro, microfilme AN_083_2006.

Processo número 13.642, fundo 84 Relação do Rio de Janeiro, série apelação cível, código de referência 84.0.ACI.00135, apelante Lúcia, apelado Mariano José Pires, ano 
inicial 1867, ano final 1872, caixa 3.696, local Minas Gerais, microfilme AN_077_2006.

Processo número 13.763, fundo 84 Relação do Rio de Janeiro, série apelação cível, código de referência 84.0.ACI.00165, apelante Ana, apelante Isabel, apelante Vitória, apelado Bernardo Gavião Ribeiro \& Gavião, ano inicial 1861, ano final 1872, caixa 3.684, local Guaratinguetá, microfilme AN_086_2006.

Processo número 13.794, fundo 84 Relação do Rio de Janeiro, série apelação cível, código de referência 84.0.ACI.00155, apelante João Xavier de Azambuja Vila Nova, apelado Joaquim, ano inicial 1869, ano final 1874, caixa 3.690, local Uruguaiana, microfilme AN_083_2006.

Processo número 14.318, fundo 84 Relação do Rio de Janeiro, série apelação cível, código de referência 84.0.ACI.00178, apelante Brasília, apelada Clélia Leopoldina Silveira, ano inicial 1871, ano final 1873, caixa 3.688, local Bahia, microfilme AN_089_2006.

Processo número 14.322, fundo 84 Relação do Rio de Janeiro, série apelação cível, código de referência 84.0.ACI.00173, apelante Francisco, apelado Afonso Levi, ano inicial 1871, ano final 1874, caixa 3.686, local São Paulo, microfilme AN_088_2006.

Processo número 14.485, fundo 84 Relação do Rio de Janeiro, série apelação cível, código de referência 84.0.ACI.00195, apelante João Ferreira de Azevedo, ano inicial 1873, ano final 1873, caixa 3.690, local Niterói, microfilme AN_095_2006.

Processo número 14.469, fundo 84 Relação do Rio de Janeiro, série apelação cível, código de referência 84.0.ACI.00194, apelante Vitorino, apelado Manuel Joaquim Gomes de Matos, ano inicial 1873, ano final 1874, caixa 3.684, local Rio de Janeiro, microfilme AN_093_2006.

\section{Coleções de jurisprudência}

Collecção chronologica dos assentos das Casas da Suplicação e do Civel. Coimbra: Real Imprensa da Universidade, 1791.

Legislação 
ALMEIDA, Candido Mendes de. Codigo philippino ou ordenações e leis do Reino de Portugal recopiladas por mandado d'El-Rey D. Philippe I. 4 livros. Rio de Janeiro: Typographia do Instituto Philomathico, 1870.

BRASIL. Lei de 13 de setembro de 1830 [online]. Regula o contracto por escripto sobre prestação de serviços feitos por Brazileiro ou estrangeiro dentro ou fóra do Imperio. [acesso em 26 de abril de 2018]. Disponível em: $<$ http://www2.camara.leg.br/legin/fed/lei_sn/1824-1899/lei-37984-13-setembro1830-565648-publicacaooriginal-89398-pl.html> .

. Lei de 16 de dezembro de 1830 [online]. Manda executar o Código Criminal. [acesso em 4 de abril de 2018]. Disponível em: $<$ http://www.planalto.gov.br/ccivil_03/leis/lim/lim-16-12-1830.htm>.

Lei de 7 de novembro de 1831 [online]. Declara livres todos os escravos vindos de fora do Império, e impõe penas aos importadores dos mesmos escravos. [acesso em 14 de abril de 2018]. Disponível em: $<$ http://www2.camara.leg.br/legin/fed/lei_sn/1824-1899/lei-37659-7-novembro1831-564776-publicacaooriginal-88704-pl.html>. . Lei de 29 de novembro de 1832 [online]. Promulga o Código do Processo Criminal de primeira instância com disposição provisória acerca da administração da Justiça Civil. [acesso em 14 de abril de 2018]. Disponível em: $<$ http://www.planalto.gov.br/ccivil_03/Leis/LIM/LIM-29-11-1832.htm>. Lei n. 108 de 11 de outubro de 1837 [online]. Dando varias providencias sobre os Contractos de locação de serviços dos Colonos. [acesso em 26 de abril de 2018]. Disponível em: $\quad<$ http://legis.senado.leg.br/legislacao/PublicacaoSigen.action? id $=541072 \&$ tipoDocumento $=$ LEI-n\&tipoTexto $=$ PUB $>$.

. Decreto n. 151 de 11 de abril de 1842 [online]. Dando Regulamento para a arrecadação da Taxa, e Meia Siza dos escravos. [acesso em 08 de maio de 2018]. Disponível em: <http://legis.senado.leg.br/legislacao/PublicacaoSigen.action? $\mathrm{id}=386100 \&$ tipoDocumento=DEC-n\&tipoTexto $=$ PUB $>$.

Lei n. 601 de 18 de setembro de 1850 [online]. Dispõe sobre as terras devolutas do Império. [acesso em 14 de janeiro de 2018]. Disponível em: $<$ http://www.planalto.gov.br/ccivil_03/Leis/L0601-1850.htm>. 
. Decreto n. 797 de 18 de junho de 1851 [online]. Manda executar o Regulamento para a organização do Censo geral do Império. [acesso em 18 de abril de 2018]. Disponível em: <http://www2.camara.leg.br/legin/fed/decret/1824-1899/decreto797-18-junho-1851-559435-publicacaooriginal-81652-pe.html>.

. Decreto n. 798 de 18 de junho de 1851 [online]. Manda executar o Regulamento do registro dos nascimentos e óbitos. [acesso em 18 de abril de 2018]. Disponível em: <http://www2.camara.leg.br/legin/fed/decret/1824-1899/decreto-798-18-junho1851-559436-publicacaooriginal-81654-pe.html>.

. Decreto n. 1.318 de 30 de janeiro de 1854 [online]. Manda executar a Lei n. 601 de 18 de Setembro de 1850. [acesso em 10 de maio de 2018]. Disponível em: $<$ http://www.planalto.gov.br/ccivil_03/decreto/1851-1899/d1318.htm>.

. Lei n. 1.237 de 24 de setembro de 1864 [online]. Reforma a Legislação Hypothecaria, e estabelece as bases das sociedades de credito real. [acesso em 10 de maio de 2018]. Disponível em: $<$ http://www.planalto.gov.br/ccivil_03/leis/lim/LIM1237impressao.htm>.

. Collecção das decisões do governo do Imperio do Brasil de 1868. Tomo XXXI.

Rio de Janeiro: Typographia Nacional, 1868.

. Lei n. 2.040 de 28 de setembro de 1871 [online]. Declara de condição livre os filhos de mulher escrava que nascerem desde a data desta lei, libertos os escravos da Nação e outros, e providencia sobre a criação e tratamento daquelles filhos menores e sobre a libertação annual de escravos. [acesso em 07 de maio de 2018]. Disponível em: <http://www.planalto.gov.br/ccivil_03/Leis/LIM/LIM2040.htm>.

. Decreto n. 4.835 de $1^{\circ}$ de dezembro de 1871 [online]. Approva o Regulamento para a matricula especial dos escravos e dos filhos livres de mulher escrava. [acesso em 09 de maio de 2018]. Disponível em: $<$ http://www2.camara.leg.br/legin/fed/decret/1824-1899/decreto-4835-1-dezembro1871-552265-publicacaooriginal-69374-pe.html>.

. Decreto n. 2.827 de 15 de março de 1879 [online]. Dispondo o modo como deve ser feito o contrato de locação de serviços. [acesso em 26 de abril de 2018]. Disponível em: <http://www2.camara.leg.br/legin/fed/decret/1824-1899/decreto2827-15-marco-1879-547285-publicacaooriginal-62001-pl.html>. 
PORTUGAL. Codigo penal approvado por decreto de 10 de dezembro de 1852. Lisboa: Imprensa Nacional, 1855.

Livros de referência

ALMEIDA, Candido Mendes de. Atlas do Imperio do Brazil: compreendendo as respectivas divisões administrativas, ecclesiasticas, eleitoraes e judiciarias, dedicado a Sua Magestade o Imperador Senhor D. Pedro II, destinado à Instrucção Publica no Imperio com especialidade à dos Alumnos do Imperial Collegio de Pedro II. Rio de Janeiro: Lithographia do Instituto Philomathico, 1868.

BLUTEAU, Raphael. Vocabulario portuguez, e latino: aulico, anatomico, architectonico, bellico, botanico, brasilico, comico, critico, chimico, dogmatico, dialectico, dendrologico, ecclesiastico, etymologico, economico, florifero, forense, fructifero, geographico, geometrico, gnomonico, hydrographico, homonymico, hierologico, ichtyologico, indico, isagogico, laconico, liturgico, lithologico, medico, musico, meteorologico, nautico, numerico, neoterico, ortographico, optico, ornithologico, poetico, philologico, pharmaceutico, quidditativo, qualitativo, quantitativo, rethorico, rustico, romano, symbolico, synonimico, syllabico, theologico, terapteutico, technologico, uranologico, xenophonico, zoologico, autorizado com exemplos dos melhores escritores portugueses, e latinos; e offerecido a El Rey de Portugal, D. João V. 8 tomos. Coimbra: Collegio das Artes da Companhia de JESU, 1712.

SILVA, Antonio de Moraes. Diccionario da lingua portugueza. 2 tomos. Lisboa: Officina de Simão Thaddeo Ferreira, 1789.

Livros jurídicos

ALENCAR, José. A propriedade. Brasília: Senado Federal, 2004. [Edição fac-similar].

ALVES JUNIOR, Thomaz. Annotações theoricas e praticas ao Codigo Criminal. 3 tomos. Rio de Janeiro: Francisco Luiz Pinto \& C., 1864.

BLACKSTONE, William. Commentaries on the Laws of England. Book II: Of the Rights of Things. Oxford: Oxford University Press, 2016. 
CARNEIRO, Manuel Borges. Direito civil de Portugal, contendo três livros: I. Das pessoas, II. Das cousas, III. Das obrigações e acções. 2 tomos. Lisboa: Typographia de Antonio José da Rocha, 1851.

FILGUEIRAS JUNIOR, Araujo. Codigo criminal do Imperio do Brazil anotado com os actos dos poderes legislativo, executivo e judiciário que têm alterado $e$ interpretado suas disposições desde que foi publicado, e com o calculo das penas em todas as suas applicações. Rio de Janeiro: Eduardo \& Henrique Laemmert, 1876.

FREIRE, Pascoal José de Melo. Instituições de direito civil português tanto público como particular [online]. Tradução disponível na Biblioteca Digital da Faculdade de Direito da Universidade de Lisboa. 4 livros. Coimbra: Typis Academicis, 1815. [acesso 12 de fevereiro de 2018]. Disponível em: $<$ http://www.fd.unl.pt/Anexos/Investigacao/1563.pdf $>$.

LUIZ, Francisco. Codigo criminal do Imperio do Brazil theorica e praticamente annotado. Maceió: Typographia de T. de Menezes, 1885.

LOBÃO, Manuel de Almeida e Sousa de. Tratado encyclopedico, compendiario, pratico e systematico dos interdictos e remedios possessorios geraes e especiaes conforme o direito romano, patrio e uso das nações. Lisboa: Imprensa Nacional, 1867.

LOUREIRO, Lourenço Trigo de. Instituições de direito civil brasileiro: extrahidas das Instituições de Direito Civil Lusitano do eximio jurisconsulto portuguez Paschoal José de Mello Freire, na parte compativel com as instituições da nossa cidade, e augmentadas nos lugares competentes com a substancia das leis brasileiras. Pernambuco: Typographia da Viuva Roma \& Filhos, 1851.

- Instituições de direito civil brasileiro: segunda edição mais correcta e augmentada, e offerecida, dedicada e consagrada a Sua Magestade Imperial o Senhor Dom Pedro II. 2 tomos. Recife: Typographia Universal, 1857.

- Instituições de direito civil brasileiro: terceira edição mais correcta, e augmentada, e offerecida, dedicada, e consagrada à Sua Magestade Imperial o Senhor Dom Pedro II. 2 tomos. Recife: Typographia Universal, 1861.

MALHEIRO, Agostinho Marques Perdigão. A escravidão no Brasil: ensaio historicojuridico-social. 3 tomos. Rio de Janeiro: Typographia Nacional, 1866. 
MOURA, Antonio Ribeiro de. Manual do edificante do proprietario e do inquilino ou novo tratado dos direitos e obrigações sobre a edificação de casas e ácerca do arrendamento ou aluguer das mesmas conforme o direito romano, patrio e o uso das nações, seguido da exposição das acções judiciaes que competem ao edificante, ao proprietario e ao inquilino accommodado ao foro do Brazil. Rio de Janeiro: Laemmert \& C, sem data.

PEREIRA, Bento. Promptuarium juridicum. Évora: Tipografia Acadêmcia, 1690.

PEREIRA, João Baptista. Codigo criminal do Imperio do Brasil annotado com os actos do Poder Legislativo e avisos do governo que hão alterado e explicado algumas de suas disposições e com as decisões do Supremo Tribunal de Justiça e da Relação do Rio de Janeiro. Rio de Janeiro: Editor E. A. de Oliveira, 1869.

PEREIRA, Lafayette Rodrigues. Direitos de família. Rio de Janeiro: B. L. Garnier Livreiro-Editor, 1869.

Direito das cousas. Rio de Janeiro: B. L. Garnier, 1877.

PESSOA, Vicente Alves de Paula. Codigo criminal do Imperio do Brazil anotado com leis, decretos, jurisprudencia dos tribunaes do paiz e avisos do governo até o fim de 1876 contém além disso muita materia de doutrina, com esclarecimentos e um índice alfabético. Rio de Janeiro: Livraria Popular, 1877.

PHAEBO, Melchior. Decisiones Senatus Regni Lusitaniae. Lisboa: Tipografia Ferreiriana, 1737. Tomo 2.

RIBAS, Antonio Joaquim. Da posse e das acções possessorias: segundo o direito patrio comparado com o direito romano e canonico. Rio de Janeiro: H. Laemmert \& C. Livreiros-Editores, 1883.

SOARES, Antonio Joaquim de Macedo. Tractado juridico-practico da medição e demarcação das terras tanto particulares, como publicas, para uso dos juizes, advogados, escrivães, pilotos e mais pessoal dos juizos divisorios. Rio de Janeiro: Typographia Polytechnica, 1882.

SOUSA, Joaquim José Caetano Pereira e. Esboço de hum diccionario juridico, theoretico, e practico, remissivo às leis compiladas, e extravagantes. 2 tomos. Lisboa: Typographia Rollandiana, 1825.

. Primeiras linhas sobre o processo civil. 3 tomos. Coimbra: Imprensa Litteraria, 1872. 
TEIXEIRA, Antonio Ribeiro de Liz. Curso de direito civil portuguez para o anno lectivo de 1843-1844; ou commentario às Instituições do Sr. Paschoal José de Mello Freire sobre o mesmo direito. 2 tomos. Coimbra: Imprensa da Universidade, 1845. TINÔCO, Antonio Luiz Ferreira. Codigo criminal do Imperio do Brazil anotado. Rio de Janeiro: Imprensa Industrial, 1886.

Manuais de agricultores

TAUNAY, Carlos Augusto. Manual do agricultor brasileiro, obra indispensavel a todo o Senhor de Engenho, Fazendeiro e Lavrador, por apresentar uma idéa geral e philosophica da Agricultura applicada ao Brazil, e ao seu especial modo de producção, bem como noções exactas sobre todos os generos de cultura em uso, ou cuja adopção fôr proficua, e tambem hum resumo de horticultura, seguido de hum epitome dos principios de botanica, e hum tratado das principaes doenças que atacão os pretos; ornado com varias estampas; segunda edição dedicada ao Exmo Sr. Senador Bernardo Pereira de Vasconcellos, Ministro da Justiça e interinamente do Imperio. Rio de Janeiro: Typographia Imperial, e Constitucional de J. Villeneuve e Comp., 1839.

WERNECK, Francisco Peixoto de Lacerda. Memoria sobre a fundação e costeio de uma fazenda na Provincia do Rio de Janeiro. Rio de Janeiro: Eduardo \& Henrique Laemmert, 1863.

Periódicos

Correio Mercantil, ano 14, n. 87, 30 de março de 1857, Rio de Janeiro, proprietário J. F. Alves Branco Muniz Barreto.

Diario do Rio de Janeiro, ano 17, n. 4, 6 de fevereiro de 1838, Rio de Janeiro, Typographia do Diario, proprietário N. L. Vianna.

Projetos de códigos e consolidações 
ARAUJO, José Thomáz Nabuco de. Codificação civil: projecto. Rio de Janeiro: Typographia Perseverança, 1878.

FREITAS, Augusto Teixeira de. Consolidação das leis civis. Rio de Janeiro: B. L. Garnier, 1876.

. Código civil: esboço. 4 tomos. Rio de Janeiro: Ministério da Justiça e Negócios Interiores, 1952.

PEREIRA, José Clemente. Projecto do codigo criminal do Império do Brasil. Rio de Janeiro: Tipografia Imperial e Nacional, 1827.

SANTOS, Joaquim Felicio dos. Projecto do codigo civil brazileiro. Rio de Janeiro: Typographia Nacional, 1882.

VASCONCELLOS, Bernardo Pereira de. Projecto do codigo criminal: apresentado em sessão de 4 de Maio de 1827. [online]. [acesso 14 de abril de 2018]. Disponível em: $<\mathrm{http}$ ://imagem.camara.gov.br/dc_20b.asp?

selCodColecaoCsv $=$ A\&Datain $=3 / 9 / 1829 \# />$

Outros documentos impressos

BRASIL. Falas do Trono: desde o ano de 1823 até o ano de 1889. Rio de Janeiro: Imprensa Oficial, 1839.

. Trabalho sobre a extincção da escravatura no Brasil. Rio de Janeiro: Typographia Nacional, 1868.

. Elemento servil: parecer e projecto de lei apresentados à Camara dos Srs. Deputados na sessão de 16 de agosto de 1870 pela commissão especial nomeada pela mesma Camara em 24 de maio de 1870. Rio de Janeiro: Typographia Nacional, 1870.

. DIRETORIA GERAL DE ESTATÍSTICA. Recenseamento Geral do Império de 1872, quadros gerais, recenseamento da população do Imperio do Brazil a que se procedeu no dia $1^{o}$ de agosto de 1872. Rio de Janeiro: Typographia de G. Leuzinger e Filhos, 1876.

. Organisações e programmas ministeriaes desde 1822 a 1889. Notas explicativas sobre moções de confiança, com alguns dos mais importantes Decretos e Leis, resumo historico sobre a discussão do Acto Addicional, Lei de Interpretação, 
Codigo Criminal, do Processo e Commercial, lei de terras, etc., etc., com varios esclarecimentos e quadros estatísticos. Rio de Janeiro: Imprensa Nacional, 1889. . Annaes do Senado do Imperio do Brazil, segunda sessão da primeira legislatura de 4 de Maio a 17 de Junho de 1839. Rio de Janeiro, 1912. Tomo I.

\section{Bibliografia}

ALEGRIO, Leila Vilela. Donas do café: mulheres fazendeiras no Vale do Paraíba (Rio de Janeiro, século XIX). Rio de Janeiro: Letra Capital, 2011.

ALENCASTRO, Luiz Felipe de. O trato dos viventes: formação do Brasil no Atlântico Sul. São Paulo: Companhia das Letras, 2000.

. "O pecado original da sociedade e da ordem jurídica brasileira", Novos estudos: Cebrap, vol. 87, 2010, pp. 5-11.

ALEXANDRE, Valentim; DIAS, Jill. O império africano (1825-1890). Lisboa: Editorial Estampa, 1998.

ALGRANTI, Leila Mezan. O feitor ausente: estudos sobre a escravidão urbana no Rio de Janeiro (1808-1822). Petrópolis: Vozes, 1988.

ALMEIDA, Joseph Cesar Ferreira de. Entre engenhos e canaviais: senhoras do açúcar em Itu (1780-1830). Dissertação de mestrado. São Paulo: Faculdade de Filosofia, Letras e Ciências Humanas, Universidade de São Paulo, 2008.

ALVEAL, Carmen Margarida Oliveira. Identidades senhoriais e conflitos: convertendo terra em propriedade no mundo atlântico português (séculos XVI-XVIII). Tese de doutorado. Boston: John Hopkins University, 2011.

AMARAL, Isabela Guimarães Rabelo do. Resistência feminina no Brasil oitocentista: as ações de divórcio e nulidade de matrimônio no bispado de Mariana. Dissertação de mestrado. Belo Horizonte: Faculdade de Direito, Universidade Federal de Minas Gerais, 2012.

ARIZA, Marília Bueno de Araújo. O oficio da liberdade: trabalhadores libertandos em São Paulo e Campinas (1830-1888). São Paulo: Alameda, 2014. 
AZCUY AMEGHINO, Eduardo. El latifundio y la gran propiedad colonial rioplatense. Cochabamba: García Cambeiro, 1995.

BALTAZAR, Miguel, CARDIM, Pedro. “A difusão da legislação régia (1621-1808)". FRAGOSO, João; MONTEIRO, Nuno Gonçalo (organizadores). Um reino e suas repúblicas no Atlântico: comunicações politicas entre Portugal, Brasil e Angola nos séculos XVII e XVIII. Rio de Janeiro: Civilização Brasileira, 2017.,pp. 161-207.

BANNER, Stuart. "Why Terra Nullius? Anthropology and Property Law in Early Australia", Law and History Review, vol. 23, n. 1, 2005, pp. 95-131.

BARBOSA, Samuel Rodrigues. "Indeterminação do constitucionalismo imperial lusobrasileiro e o processo de independência do Brasil (1821-1822)". BARBOSA, Samuel Rodrigues; PEREZ-COLLADOS, José María (orgs.). Juristas de la independencia. Madrid: MArcial Pons, 2012, pp. 103-129.

BASTIAS SAAVEDRA, Manuel. "The Lived Space: Possession, Ownership, and Land Sales on the Chilean Frontier (Valdivia, 1790-1830)", Historia Critica, n. 67, 2018, pp. 3-21.

BEN PLOTKIN, Mariano; ZIMMERMANN, Eduardo (compiladores). Los saberes del estado. Buenos Aires: Edhasa, 2012.

BIRR, Christiane. Rechte im Strom der Zeit: Die Entstehung der unvordenklichen Verjährung. Tese de Habilitação. Würzburg: Juristischen Fakultät, Bayerischen Julius-Maximilians-Universität Würzburg, 2010.

BISSIGO, Diego Nones. $O$ censo e as nações: os africanos nos levantamentos populacionais no Brasil do século XIX. Monografia de conclusão de curso. Florianópolis: Centro de Filosofia e Ciências Humanas, Universidade Federal de Santa Catarina, 2010.

BLAUFARB, Rafe. The Great Demarcation: the French Revolution and the Invention of Modern Property. Oxford: Oxford University Press, 2016.

BOTELHO, Tarcísio. "Censos e construção nacional no Brasil Imperial”, Tempo Social, vol. 17 , n. 1, 2005, pp. 321-341.

CABRAL, Gustavo César Machado. Literatura jurídica na idade moderna: as decisiones no Reino de Portugal (séculos XVI e XVII). Rio de Janeiro: Lumen Juris, 2017. 
CAÉ, Rachel da Silveira; GRINBERG, Keila. "Escravidão, fronteira e relações diplomáticas Brasil-Uruguai (1840-1860)”, Africana Studia, n. 14, 2010, pp. 275285.

CAMARINHAS, Nuno. "Justice Administration in Early Modern Portugal: Kingdom and Empire in a Bureaucratic Continuum”, Portuguese Journal of Social Science, vol. 12, n. 2, pp. 179-193.

CAMPOS, Adriana Pereira. "Prescrição da escravidão e a 'liberdade oprimida' no Brasil do oitocentos", História (São Paulo), vol. 34, n. 2, 2015, pp. 206-220.

CANDIDO, Mariana. Fronteras de esclavización: esclavitud, comercio e identidad en Benguela (1780-1850). México DF: El Colegio de México, 2011.

. "African Freedom Suits and Portuguese Vassal Status: Legal Mechanisms for Fighting Enslavement in Benguela, Angola (1800-1830)", Slavery \& Abolition, vol. 32, n. 3, 2011, pp. 447-459.

. An African Slaving Port and the Atlantic World: Benguela and Its Hinterland. Cambridge: Cambridge University Press, 2013.

. "South Atlantic Exchanges: the Role of Brazilian-Born Agents in Benguela (16501850)", Luso-Brazilian Review, v. 50, n. 1, 2013, pp. 53-82.

- "O limite tênue entre liberdade e escravidão em Benguela durante a era do comércio transaltântico", Afro-Ásia, vol. 47, 2013, pp. 239-268.

. "Women, Family, and Landed Property in Nineteenth-Century Benguela", African Economic History, vol. 43, 2015, pp. 136-161.

CANDIDO, Mariana; RODRIGUES, Eugénia. “African Women's Access and Rights to Property in the Portuguese Empire", African Economic History, vol. 43, 2015, pp. $1-18$.

CARVALHO, José Murilo de. A construção da ordem: a elite política imperial/Teatro de sombras: a política imperial. Rio de Janeiro: Civilização Brasileira, 2008.

CARVALHO, Marcus de; GOMES, Flávio dos Santos; REIS, João José. O Alufá Rufino: tráfico, escravidão e liberdade no Atlântico Negro (c. 1822-c. 1853). São Paulo: Companhia das Letras, 2010.

CHALHOUB, Sidney. Visões da liberdade: uma história das últimas décadas da escravidão na corte. São Paulo: Companhia das Letras, 1990. . Machado de Assis, historiador. São Paulo: Companhia das Letras, 2003. 
- "The Precariousness of Freedom in a Slave Society (Brazil in the Nineteenth Century)", International Review of Social History, vol. 56, n. 3, 2011, pp. 405-439. . A força da escravidão: ilegalidade e costume no Brasil oitocentista. São Paulo: Companhia das Letras, 2012.

CHRISTILLINO, Cristiano Luís. Litígios ao sul do Império: a Lei de Terras e a consolidação política da Coroa no Rio Grande do Sul (1850-1880). Tese de Doutorado. Niterói: Instituto de Ciências Humanas e Filosofia, Universidade Federal Fluminense, 2010.

CLAVERO, Bartolomé. "Les domaines de la propriété (1789-1814): propiedades y propiedad en el laboratorio revolucionario", Quaderni Fiorentini per la Storial del Pensiero Giuridico Moderno, vol. 27, 1998, pp. 269-378.

COHN, Marjorie Rocha. A Fazenda Santa Sofia: cafeicultura e escravidão no Vale do Paraíba mineiro (1850-1882). Dissertação de mestrado. São Paulo: Faculdade de Filosofia, Letras e Ciências Humanas, Universidade de São Paulo, 2013.

CONGOST, Rosa. Tierras, leyes, historia: estudios sobre "la gran obra de la propiedad". Barcelona: Crítica, 2007.

CONTE, Emanuele. Servi medievali: dinamiche del diritto comune. Roma: Viella, 1996.

CONTE, Emanuele; MANNINO, Vicenzo; VECCHI, Paolo Maria. Uso, tempo, possesso dei diritti: una ricerca storica e di diritto positivo. Torino: G. Giappichelli Editore, 1999.

CORRÊA, Dora Shellard. Paisagens sobrepostas: indios, posseiros e fazendeiros nas matas de Itapeva (1723-1930). Londrina: EDUEL, 2013.

COSTA, Vivian Chieregati. Codificação e formação do Estado-nacional brasileiro: o Código Criminal de 1830 e a positivação das leis no pós-Independência. Dissertação de mestrado. São Paulo: Instituto de Estudos Brasileiros, Universidade de São Paulo, 2013.

COWLING, Camillia. Conceiving Freedom: Women of Color, Gender, and the Abolition of Slavery in Havana and Rio de Janeiro. Chapel Hill: The University of North Carolina Press, 2013.

D’AGOSTINO, Valeria. Expansión de la frontera y ocupación del nuevo sur: los partidos de Arenales y Ayacucho (Provincia de Buenos Aires, 1820-1900). Buenos Aires: Prometeo Libros, 2012. 
DANWERTH, Otto. "La circulación de literatura normativa pragmática en Hispanoamérica (siglos XVI-XVII)". DUVE, Thomas (organizador). Actas del XIX Congreso del Instituto Internacional de Historia del Derecho Indiano. Madrid: Editorial Dykinson. tomo 1, pp. 359-400.

DECOCK, Wim. Theologians and Contract Law: The Moral Transformation of the Ius Commune (ca. 1500-1650). Leiden: Martinus Nijhoff Publishers, 2013.

DE LA FUENTE, Alejandro. "Slaves and the Creation of Legal Rights in Cuba: Coartación and Papel”, Hispanic American Historical Review, vol. 87, n. 4, 2007, pp. 659-692.

DE LA PUENTE LUNA. José Carlos. “Cuando el 'punto de vista nativo' no es el punto de vista de los nativos: Felipe Guaman Poma de Ayala y la apropiación de tierras en el Perú colonial", Bulletin de l'Institut français d'études andines, vol. 37, n. 1, 2008, pp. 123-149.

DIAS PAES, Mariana Armond. Sujeitos da história, sujeitos de direitos: personalidade jurídica no Brasil escravista (1860-1888). Dissertação de mestrado. São Paulo: Faculdade de Direito, Universidade de São Paulo, 2014.

. "O procedimento de manutenção de liberdade no Brasil oitocentista", Estudos Históricos, vol. 29, n. 58, 2016, pp. 339-360.

- "Sobre origens, continuidades e criações: a posse da liberdade nos decisionistas portugueses (sécs. XVI-XVIII) e no direito da escravidão (séc. XIX)”. DUVE, Thomas (organizador). Actas del XIX Congreso del Instituto Internacional de Historia del Derecho Indiano. Madrid: Editorial Dykinson. tomo 2, pp. 1379-1406.

DIÓRIO, Renata Romualdo. As marcas da liberdade: trajetórias sociais dos libertos em Mariana na segunda metade do século XVIII. Dissertação de mestrado. São Paulo: Faculdade de Filosofia, Letras e Ciências Humanas, Universidade de São Paulo, 2007.

DIREITO, Bárbara; MIRANDA, Susana Münch; RODRIGUES, Eugénia; SERRÃO, José Vicente (editors). Property Rights, Land and Territory in the European Overseas Empires. Lisboa: Centro de Estudos de História Contemporânea, 2014.

DORNELLES, Soraia Sales. A questão indígena e o Império: indios, terra, trabalho e violência na província paulista (1845-1891). Tese de Doutorado. Campinas: 
Instituto de Filosofia e Ciências Humanas, Universidade Estadual de Campinas, 2017.

DUVE, Thomas. "European Legal History: Concepts, Methods, Challenges". DUVE, Thomas (editor). Entanglements in Legal History: Conceptual Approaches. Frankfurt am Main: Max Planck Institute for European Legal History. pp. 29-66.

. "Was ist 'Multinormativität'? Einführende Bemerkungen", Rechtsgeschichte Legal History, vol. 25, 2017, pp. 88-101.

ESPÍNDOLA, Ariana Moreira. Papéis da escravidão: a matrícula especial de escravos (1871). Tese de doutorado. Florianópolis: Centro de Filosofia e Ciências Humanas, Universidade Federal de Santa Catarina, 2016.

FARGE, Arlette. O sabor do arquivo. São Paulo: Editora da Universidade de São Paulo, 2009.

FERRARO, Marcelo Rosanova. A arquitetura da escravidão nas cidades do café: Vassouras, século XIX. Dissertação de mestrado. São Paulo: Faculdade de Filosofia, Letras e Ciências Humanas, Universidade de São Paulo, 2017.

FERREIRA, Roquinaldo. Cross-Cultural Exchange in the Atlantic World: Angola and Brazil during the Era of the Slave Trade. Cambridge: Cambridge University Press, 2012.

FRANCO, Maria Sylvia de Carvalho. Homens livres na ordem escravocrata. São Paulo: Fundação Editora da Unesp, 1997.

FREITAS, Judy Bieber. "Slavery and Social Life: Attempts to Reduce Free People to Slavery in the Sertão Mineiro, Brazil (1850-1871)", Journal of Latin American Studies, vol. 26, n. 3, pp. 597-619.

GALEANO, Diego. Criminosos viajantes: circulações transnacionais entre Rio de Janeiro e Buenos Aires (1890-1930). Rio de Janeiro: Arquivo Nacional, 2016.

GARAVAgLIA, Juan Carlos. Pastores y labradores de Buenos Aires: una historia agraria de la campaña bonaerense (1700-1830). Buenos Aires: Ediciones de la Flor, 1999.

GARAVAGLIA, Juan Carlos; GAUTREAU, Pierre (editores). Mensurar la tierra, controlar el territorio: América Latina, siglos XVIII-XIX. Rosario: Prohistoria, 2011. 
GARCIA, Elisa Frühauf. As diversas formas de ser índio: politicas indígenas e politicas indigenistas no extremo sul da América portuguesa. Rio de Janeiro: Arquivo Nacional, 2009.

GARCÍA MARTÍNEZ, Orlando; ZEUSKE, Michael. "Estado, notarios y esclavos en Cuba: aspectos de una genealogía legal de la ciudadanía en sociedades esclavistas”, Nuevo Mundo, Mundos Nuevos, n. 8, 2008.

GARRIGA, Carlos. “Orden jurídico y poder político en el Antiguo Régimen”. GARRIGA, Carlos; LORENTE, Marta. Cádiz, 1812: la constitución jurisdiccional. Madrid: Centro de Estudios Políticos y Constitucionales, 2007. pp. 43-72.

GAUDIN, Guillaume. El imperio de papel de Juan Díez de la Calle: pensar y gobernar el Nuevo Mundo en el siglo XVII. Madrid: Fondo de Cultura Económica de España, 2017.

GELMAN, Jorge. Campesinos y estancieros: una región del Río de la Plata a fines de la época colonial. Buenos Aires: Editorial Los Libros del Riel, 1998.

GONZÁlEZ UNDURRUAGA, Carolina; VELÁZQUEZ, María Elisa (coordinadoras). Mujeres africanas y afrodescendientes: experiencias de esclavitud y libertad en América Latina y África (siglos XVI al XIX). México: Instituto Nacional de Antropología e Historia, 2016.

GORDON, Robert. “Critical Legal Histories”, Stanford Law Review, vol. 36, 1984, pp. 57 125.

GRAUBART, Karen. "Shifting Landscapes: Heterogeneous Conceptions of Land Use and Tenure in the Lima Valley", Colonial Latin American Review, vol. 26, n. 1, pp. 6284.

GREER, Allan. Property and Dispossession: Natives, Empires and Land in Early Modern North America. Cambridge: Cambridge University Press, 2018.

GRINBERG, Keila (organizadora). As fronteiras da escravidão e da liberdade no sul da América. Rio de Janeiro: 7 Letras, 2013.

GRINBERG, Keila. "Re-enslavement, Rights and Justice in Nineteenth-Century Brazil”, Translating the Americas, vol. 1, 2013, pp. 141-159.

- "Illegal Enslavement, International Relations, and International Law on the Southern Border of Brazil", Law and History Review, vol. 35, n. 1, 2016, pp. 31-52. 
GRINBERG, Keila; MAMIGONIAN, Beatriz Gallotti. "Le crime de réduction à l'esclavage d'une personne libre (Brésil, XIX ${ }^{\mathrm{e}}$ siècle)", Brésil(s): sciences humaines et sociales, vol. 11, 2017.

GRINBERG, Keila; SILVA, Cristina Nogueira da. "Soil Free from Slaves: Slave Law in Late Eighteenth and Early Nineteenth Century Portugal”, Slavery \& Abolition, vol. 32, n. 3, 2011, pp. 431-446.

GROSS, Ariela. "Litigating Whiteness: Trials of Racial Determination in the NineteenthCentury South", The Yale Law Journal, vol. 108, n. 109, 1998, pp. 109-188.

- What Blood Won't Tell: a History of Race on Trial in America. Cambridge: Harvard University Press, 2008.

GROSSI, Paolo. Il dominio e le cose: percezioni medievali e moderne dei diritti reali. Milano: Giuffrè Editore, 1992. . El orden jurídico medieval. Madrid: Marcial Pons, 1995.

GUEDES, Roberto. “Casas e sanzalas (Benguela, 1797-1798)”, Veredas da História, n. 1, 2014, pp. 55-85.

GUIMARÃES, Elione. Terra de preto: usos e ocupação da terra por escravos e libertos (Vale do Paraíba mineiro, 1850-1920). Niterói: Editora da Universidade Federal Fluminense, 2009.

HALPÉRIN. Histoire du droit des biens. Paris: Economica, 2008.

HÉBRARD, Jean; SCOTT, Rebecca. Provas de liberdade: uma odisseia atlântica na era da emancipação. Campinas: Editora da Unicamp, 2014.

HERZOG, Tamar. Upholding Justice: Society, State, and the Penal System in Quito (16501750). Ann Arbor: The University of Michigan Press, 2007.

. Frontiers of possession: Spain and Portugal in Europe and the Americas. Cambridge: Harvard University Press, 2015.

HESPANHA, António Manuel. "Direito comum e direito colonial”, Panóptica, n. 3, 2006, pp. 95-116.

. Imbecillitas: as bem-aventuranças da inferioridade nas sociedades de Antigo Regime. São Paulo: Annablume, 2010.

. Como os juristas viam o mundo, 1550-1750: direitos, estados, pessoas, coisas, contratos, ações e crimes. Lisboa: António Manuel Hespanha, 2015. 
HUNT, Lynn. A invenção dos direitos humanos: uma história. São Paulo: Companhia das Letras, 2007.

ILLANES OLIVA. Maria Angélica. "La cuarta frontera: el caso del território valdiviano (Chile, XVII-XIX)", Atenea, n. 509, 2014, pp. 227-243.

KARASCH, Mary. A vida dos escravos no Rio de Janeiro (1808-1850). São Paulo: Companhia das Letras, 2000.

KELLER, Arthur; LISSITZYN, Oliver; MANN, Frederick (eds.). Creation of Rights of Sovereignty Through Symbolic Acts (1400-1800). New York: AMS Press, 1967.

KEENAN, Sarah. "Smoke, Curtains and Mirrors: the Production of Race Through Time and Title Registration", Law Critique, 2016.

LAHON, Didier. "O escravo africano na vida económica e social portuguesa do Antigo Regime", Africana Studia, n. 7, 2004, pp. 73-100.

LANGFUR, Hal. The Forbidden Lands: Colonial Identity, Frontier Violence, and the Persistence of Brazil's Eastern Indians (1750-1830). Stanford: Stanford University Press, 2006.

LARA, Silvia Hunold. Campos da violência: escravos e senhores na Capitania do Rio de Janeiro (1750-1808). São Paulo: Paz e Terra, 1988.

LEIPNITZ, Guinter Tlaija. Vida independente, ainda que modesta: dependentes, trabalhadores rurais e pequenos produtores na fronteira meridional do Brasil (c. 1884-c. 1920). Tese de Doutorado. Porto Alegre: Instituto de Filosofia e Ciências Humanas, Universidade Federal do Rio Grande do Sul, 2016.

LIMA, Luciano Mendonça de. "Quebra-Quilos: uma revolta popular na periferia do Império". DANTAS, Monica Duarte (organizadora). Revoltas, motins, revoluções: homens livres pobres e libertos no Brasil do século XIX. São Paulo: Alameda, 2011. pp. 449-483.

LINEBAUGH, Peter; REDIKER, Marcus. The Many-headed Hydra: Sailors, Slaves, Commoners, and the Hidden History of the Revolutionary Atlantic. Boston: Beacon Press, 2000.

LOURENÇO, Thiago Campos Pessoa Lourenço. O império dos Souza Breves nos oitocentos: política e escravidão nas trajetórias dos Comendadores José e Joaquim de Souza Breves. Dissertação de mestrado. Niterói: Instituto de Ciências Humanas e Sociais, Universidade Federal Fluminense, 2010. 
A indiscrição como ofício: o complexo cafeeiro revisitado (Rio de Janeiro, $c$. 1830- c. 1888). Tese de doutorado. Niterói: Instituto de Ciências Humanas e Sociais, Universidade Federal Fluminense, 2015.

LORENTE SARIÑENA, Marta. "Uti possidetis, ita domini eritis: International Law and the Historiography of the Territory". MECCARELLI, Massimo; SOLLA SASTRE, María Julia (organizadores). Spatial and Temporal Dimensions for Legal History: Research Experiences and Itineraries. Frankfurt am Main: Max Planck Institute for European Legal History, 2016, pp. 131-172.

LOVEMAN, Mara. "Blinded Like a State: The Revolt against Civil Registration in Nineteenth-Century Brazil", Comparative Studies in Society and History, vol. 49, n. 1, 2007, pp. 5-39.

LUNA, Pablo. "Property, Dominium, and the Hispanic Enlightenment on Both Sides of the Atlantic in the Second Half of the Eighteenth Century". BÉAUR, Gérard; CHEVET, Jean-Michel; PÉREZ-PÍCAZO, María Teresa; SCHOFIELD, Phillipp (editors). Property Rights, Land Markets and Economic Growth in the European Coutryside (Thirteenth-Twentieth Centuries). Turnhout: Brepols Publisher, 2013. pp. 87-104.

MACHADO, Maria Helena. "Em torno da autonomia escrava: uma nova direção para a história social da escravidão", Revista brasileira de história, vol. 8, n. 16, 1988, pp. 143-160.

MACHADO, Marina Monteiro. Entre fronteiras: posses e terras indígenas nos sertões (Rio de Janeiro, 1790-1824). Guarapuava: Unicentro, 2012.

MACHADO, Marina Monteiro; MARTINS, Mônica de Souza Nunes. “A modernidade nas terias da floresta: o Brasil na Exposição Universal da Filadélfia de 1876", Geosul, vol. 32 , n. 65,2017 , pp. 68-86.

MACHADO, Marina Monteiro; MOTTA, Márcia; SERRÃO, José Vicente (organizadores). Em terras lusas: conflitos e fronteiras no Império Português. Vinhedo: Editora Horizonte, 2013.

MADEIRA-SANTOS, Catarina. "Esclavage africain et traite atlantique confrontés: transactions langagières et juridiques (à propos du tribunal de mucamos dans l'Angola des XVII ${ }^{\mathrm{e}}$ et XVIII ${ }^{\mathrm{e}}$ siècles)", Brésil(s), Sciences humaines et sociales, vol. 1, 2012. 
MAMIGONIAN, Beatriz Gallotti. “Africanos em Santa Catarina: escravidão e identidade étnica (1750-1850)". Seminário Internacional "Nas rotas do Império: eixos mercantis, tráfico de escravos, relações sociais no mundo português”, Universidade Federal do Rio de Janeiro, Rio de Janeiro, junho de 2006. [acesso 3 de abril 2018]. Disponível em: $<$ http://bgmamigo.paginas.ufsc.br/files/2011/04/BMamigonianRotas_do_Imperio.pdf>.

. "José Majojo e Francisco Moçambique, marinheiros das rotas atlânticas: notas sobre a reconstituição de trajetórias da era da abolição", Topoi, vol. 11, n. 20, 2010, pp. 75-91.

- "O Estado nacional e a instabilidade da propriedade escrava: a Lei de 1831 e a matrícula dos escravos de 1872”, Almanack, n. 2, 2011, pp. 20-37.

- "Tráfico de escravos e a presença africana na Ilha de Santa Catarina". MAMIGONIAN, Beatriz Gallotti; ZIMMERMANN, Joseane Vidal (organizadoras). História diversa: africanos e afrodescendentes na Ilha de Santa Catarina. Florianópolis: Editora da UFSC, 2013, pp. 17-42.

. Africanos livres: a abolição do tráfico de escravos no Brasil. São Paulo: Companhia das Letras, 2017.

MARQUES, João Pedro. The Sounds of Silence: Nineteenth-Century Portugal and the Abolition of the Slave Trade. New York: Berghahn Books, 2005.

MARQUESE, Rafael de Bivar. "A administração do trabalho escravo nos manuais de fazendeiro do Brasil Império (1830-1847)”, Revista de História, v. 137, 1997, pp. 95-111.

MARQUESE, Rafael de Bivar; TOMICH, Dale. "O Vale do Paraíba escravista e a formação do mercado mundial do café no século XIX”. MUAZE, Mariana; SALLES, Ricardo (organizadores). O Vale do Paraíba e o Império do Brasil nos quadros da Segunda Escravidão. Rio de Janeiro: 7 Letras, 2015. pp. 21-56.

MARTÍNEZ PÉREZ, Fernando. “'Interim apud hispanos': mandati de manutenendo y sumarísimos de posesión en la jurisprudencia moderna española", Initium, vol. 7, 2002, pp. 139-180.

MATTOS, Hebe Maria. Das cores do silêncio: os significados da liberdade no sudeste escravista (Brasil, séc. XIX). Rio de Janeiro: Nova Fronteira, 1998. 
MAYO, Carlos. Estancia y sociedad en La Pampa (1740-1820). Buenos Aires: Biblos, 2004.

MELO, Karina Moreira Ribeiro da Silva e. A aldeia de São Nicolau do Rio Pardo: histórias vividas por índios guaranis (séculos XVIII-XIX). Dissertação de Mestrado. Porto Alegre: Instituto de Filosofia e Ciências Humanas, Universidade Federal do Rio Grande do Sul, 2011.

MENDONÇA, Joseli Maria Nunes. "Sobre cadeias e coerção: experiências de trabalho no centro-sul do Brasil no século XIX”, Revista Brasileira de História, vol. 32, n. 64, 2012, pp. 45-60.

MÍGUEZ NÚÑEZ, Rodrigo. Terra di scontri: alterazioni e rivendicazioni del diritto alla terra nelle Ande centrali. Milano: Griuffrè Editore, 2013.

MILLER, Joseph. Kings and Kinsmen: Early Mbundu States in Angola. Oxford: Clarendon Press, 1976.

MONTEIRO, John Manuel. Negros da terra: índios e bandeirantes nas origens de São Paulo. São Paulo: Companhia das Letras, 1994.

MOTA, Maria Sarita. "Sesmarias e propriedade titulada da terra: o individualismo agrário na América Portuguesa”, Saeculum, n. 26, 2012, 29-45.

MOTTA, Márcia Maria Menendes. Nas fronteiras do poder: conflito e direito à terra no Brasil do século XIX. Niterói: Editora da Universidade Federal Fluminense, 2008. . Direito à terra no Brasil: a gestação do conflito (1795-1824). São Paulo: Alameda, 2009.

MUAZE, Mariana. As memórias da viscondessa: família e poder no Brasil Império. Rio de Janeiro: Jorge Zahar Editor, 2008.

NOIRIEL, Gérard. "The Identification of the Citizen: the Birth of Republican Civil Status in France". CAPLAN, Jane; TORPEY, John (editors). Documenting Individual Identity: the Development of State Practices in the Modern World. Princeton: Princeton University Press, 2001. pp. 28-48.

OLIVEIRA, Joice Fernanda de Souza. Forasteiros no Oeste Paulista: escravos no comércio interno de cativos e suas experiências em Campinas (1850-1888). Dissertação de mestrado. Campinas: Instituto de Filosofia e Ciências Humanas, Universidade Estadual de Campinas, 2013. 
OLIVEIRA, Maria Luiza Ferreira de. "Resistência popular contra o Decreto 798 ou a 'lei do cativeiro': Pernambuco, Paraíba, Alagoas, Sergipe, Ceará (1851-1852)”. DANTAS, Monica Duarte (organizadora). Revoltas, motins, revoluções: homens livres pobres e libertos no Brasil do século XIX. São Paulo: Alameda, 2011. pp. 391-427.

ORTIZ, Helen Scorsatto. Costumes e conflitos: a luta pela terra no norte do Rio Grande do Sul (Soledade, 1857-1927). Tese de Doutorado. Porto Alegre: Faculdade de Filosofia e Ciências Humanas, Pontifícia Universidade Católica do Rio Grande do Sul, 2014.

OSÓRIO, Helen. “'Estancieiros' e 'lavradores': Rio Grande do Sul, século XVIII”, Anos 90, n. 4, 1995, pp. 31-43.

. "Continuidades: estruturas agrárias e o trânsito na fronteira luso-espanhola na américa meridional", Revista Complutense de Historia de América, vol. 40, 2014, pp. 93-112.

OWENSBY, Brian. Empire of Law and Indian Justice in Colonial Mexico. Stanford: Stanford University Press, 2008.

PAIVA, Eduardo França. Escravos e libertos nas Minas Gerais do século XVIII: estratégias de resistência através dos testamentos. São Paulo: Annablume, 1995.

PAIVA, Lucas Gesta Palmares Munhoz de. "Da colonização do Vale à formação de uma família: uma introdução à história dos Werneck e suas estratégias matrimoniais". MUAZE, Mariana; SALLES, Ricardo (organizadores). O Vale do Paraíba e o Império do Brasil nos quadros da Segunda Escravidão. Rio de Janeiro: 7 Letras, 2015. pp. 176-196.

PARETO JÚNIOR, Lindener. Pândegos, rábulas, gamelas: os construtores não diplomados entre a engenharia e a arquitetura (1890-1960). Tese de Doutorado. São Paulo: Faculdade de Arquitetura e Urbanismo, Universidade de São Paulo, 2016.

PARISE, Agustín. Ownership Paradigms in American Civil Law Jurisdictions: Manifestations of the Shifts in the Legislation of Louisiana, Chile and Argentina (16 $6^{\text {th }}-20^{\text {th }}$ Centuries). Leiden: Brill, 2016.

PARRON, Tâmis. A política da escravidão no Império do Brasil (1826-1865). Rio de Janeiro: Civilização Brasileira, 2011. 
PENA, Eduardo Spiller. Pajens da casa imperial: jurisconsultos, escravidão e a Lei de 1871. Campinas: Editora da Unicamp, 2001.

PENTEADO, Luciano de Camargo. Direito das coisas. São Paulo: Editora Revista dos Tribunais, 2014.

PERERA DÍAZ, Aisnara; MERIÑO FUENTES, María de los Ángeles. Estrategias de libertad: un acercamiento a las acciones legales de los esclavos en Cuba (17621872). 2 tomos. La Habana: Editorial de ciencias sociales, 2015.

PESSOA, Fernando. Mensagem. São Paulo: Martin Claret, 2002.

PINHEIRO, Fernanda Aparecida Domingos. Em defesa da liberdade: libertos e livres de cor nos tribunais do Antigo Regime português (Mariana e Lisboa, 1720-1819). Tese de doutorado. Campinas: Instituto de Filosofia e Ciências Humanas, Universidade Estadual de Campinas, 2013.

PINTO, Francisco Eduardo. A hidra de sete bocas: sesmeiros e posseiros em conflito no povoamento das Minas Gerais (1750-1822). Juiz de Fora: Editora UFJF, 2014.

PREMO, Bianca. The Enlightenment on Trial: Ordinary Litigants and Colonialism in the Spanish Empire. Oxford: Oxford University Press, 2017.

PUTNAM, Lara. "To Study the Fragments/Whole: Microhistory and the Atlantic World", Journal of Social History, vol. 39, n. 3, 2006, pp. 615-630.

REGINALDO, Lucilene. “África em Portugal: devoções, irmandades e escravidão no Reino de Portugal (século XVIII)", História, vol. 28, n. 1, 2009, pp. 289-319.

ROBERTO, Giordano Bruno Soares. O direito civil nas Academias Jurídicas do Império. Tese de Doutorado. Belo Horizonte: Faculdade de Direito, Universidade Federal de Minas Gerais, 2008.

RODRIGUES, Eugénia; SERRÃO, José Vicente. "Migration and Accommodation of Property Rights in the Portuguese Eastern Empire (Sixteenth-Nineteenth Centuries)". CONGOST, Rosa; GELMAN, Jorge; SANTOS, Rui (editors). Property Rights in Land: Issues in Social, Economic and Global History. London: Routledge, 2017. pp. 9-31.

RODRIGUES, Pedro Parga. As frações da classe senhorial e a lei hipotecária de 1864. Tese de Doutorado. Niterói: Instituto de Ciências Humanas e Filosofia, Universidade Federal Fluminense, 2014. 
ROSE, Carol. "Possession as the Origino f Property", The University of Chicago Law Review, n. 52, 1985, pp. 73-88.

SANTOS, Catarina Madeira; TAVARES, Ana Paula. Africae Monumenta: a apropriação da escrita pelos africanos. Lisboa: Instituto de Investigação Científica Tropical, 2002.

SARMENTO, Carlos Eduardo. A medida do progresso: as elites imperiais e a adoção do sistema métrico no Brasil. Rio de Janeiro: CPDOC, 1997.

SAUNDERS, A. C. de C. M. A Social History of Black Slaves and Freedmen in Portugal (1441-1555). Cambridge: Cambridge University Press, 1982.

SCHEFFER, Rafael da Cunha. Comércio de escravos do sul para o sudeste (1850-1888): economias microrregionais, redes de negociantes e experiência cativa. Tese de doutorado. Campinas: Instituto de Filosofia e Ciências Humanas, Universidade Estadual de Campinas, 2012.

SCHWARCZ, Lilia Moritz. O espetáculo das raças: cientistas, instituições e questão racial no Brasil (1870-1930). São Paulo: Companhia das Letras, 1993. . As barbas do imperador: D. Pedro II, um monarca nos trópicos. São Paulo: Companhia das Letras, 1998.

SCOTT, James. Seeing Like a State: How Certain Schemes to Improve the Human Condition Have Failed. New Haven: Yale University Press, 1998.

SCOTT, Rebecca. "Small-Scale Dynamics of Large-Scale Processes", The American Historical Review, vol. 105, n. 2, 2000, pp. 472-479.

. "Slavery and the Law in Atlantic Perspective: Jurisdiction, Jurisprudence, and Justice", Law and History Review, vol. 29, n. 4, 2011, pp. 915-924.

- "Paper Thin: Freedom and Re-enslavement in the Diaspora of the Haitian Revolution”, Law and History Review, vol. 29, n. 4, 2011, pp. 1061-1087.

. "Social Facts, Legal Fictions, and the Attribution of Slave Status: The Puzzle of Prescription", Law and History Review, vol. 35, n. 1, 2017, pp. 9-30.

SEED, Patricia. Ceremonies of Possession in the Europe's Conquest of the New World (1492-1640). Cambridge: Cambridge University Press, 1995.

SILVA, Cristina Nogueira da. Constitucionalismo e império: a cidadania no ultramar português. Coimbra: Almedina, 2009. 
A construção jurídica dos Territórios Ultramarinos Portugueses no século XIX: modelos, doutrinas e leis. Lisboa: Instituto de Ciências Sociais, 2017.

SILVA, Luiz Geraldo. "Esperança de liberdade: interpretações populares da abolição ilustrada (1773-1774)", Revista de História, vol. 144, 2001, pp. 107-149.

SILVA, Lígia Osório. Terras devolutas e latifúndio: efeitos da Lei de 1850. Campinas: Editora da Unicamp, 1996.

SILVA JÚNIOR. Waldomiro Lourenço da. Entre a escrita e a prática: direito e escravidão no Brasil e em Cuba (c. 1760-1871). Tese de doutorado. São Paulo: Faculdade de Filosofia, Letras e Ciências Humanas, Universidade de São Paulo, 2015.

SLENES, Robert Wayne. The Demography and Economics of Brazilian Slavery (18501888). Tese de doutorado. Palo Alto: History Department, Stanford University, 1976.

. “Malungo, ngoma vem!': África coberta e descoberta do Brasil”, Revista Usp, n. 12, 1992, pp. 48-67.

. Na senzala, uma flor: esperanças e recordações na formação da família escrava (Brasil, Sudeste, século XIX). Campinas: Editora da Unicamp, 2011.

SOARES, Luiz Carlos. "Os escravos de ganho no Rio de Janeiro do século XIX", Revista Brasileira de História, vol. 8, n. 16, 1988, pp. 107-142.

STOLZENBERG, Nomi Maya. "Facts on the Ground". ALEXANDER, Gregory; PEÑALVER, Eduardo (organizadores). Property and Community. Oxford: Oxford University Press, 2010. pp. 107-139.

TAU ANZOÁTEGUI, Víctor. Casuismo y sistema: indagación histórica sobre el espíritu del derecho indiano. Buenos Aires: Instituto de Investigaciones de Historia del Derecho, 1992.

TELL, Sonia. Córdoba rural: una sociedad campesina (1750-1850). Buenos Aires: Prometeo Libros, 2008.

TESTUZZA, Maria Sole. "Ius corporis, quasi ius de corpore disponendi": il "Tractatus de Potestate in Se Ipusum” di Baltasar Gómez de Amescúa. Milano: Giuffrè Editore, 2016.

THOMPSON, Edward Palmer. Whigs and Hunters: the Origin of the Black Act. London: Penguin Books, 1990. 
TREECE, David. Exiles, Allies, Rebels: Brazil's Indianist Movement, Indigenist Politics, and the Imperial Nation-State. London: Greenwood Press, 2000.

VALLEJO, Jesus. Ruda equidad, ley consumada: concepción de la potestad normativa (1250-1350). Madrid: Centro de Estudios Constitucionales, 1992.

. "El cáliz de plata: articulación de órdenes jurídicos en la jurisprudencia del ius commune", Revista de Historia del Derecho, vol. 38, 2009, pp. 1-13.

VANSINA, Jan. How Societies are Born: Governance in West Central Africa Before 1600. Charlottesville: University of Virginia Press, 2004.

VARELA, Laura Beck. Das sesmarias à propriedade moderna: um estudo de história do direito brasileiro. Rio de Janeiro: Renovar, 2005.

VEIGA, Cristiane Fernandes Lopes. Vida após a morte: mulheres viúvas nas malhas do Império Luso, Rio de Janeiro (c. 1763-1808). Tese de Doutorado. São Paulo: Faculdade de Filosofia, Letras e Ciências Humanas, Universidade de São Paulo, 2017.

VILLA, Carlos Eduardo Valencia. Produzindo alforrias no Rio de Janeiro no século XIX. Dissertação de Mestrado. Rio de Janeiro: Instituto de Filosofia e Ciências Humanas, Universidade Federal do Rio de Janeiro, 2008.

WELKE, Barbara Young. Law and the Borders of Belonging in the Long Nineteenth Century United States. Cambridge: Cambridge University Press, 2010.

WIESE, Marion. Leibeigene Bauern und Römisches Recht im 17. Jahrhundert: ein Gutachten des David Mevius. Berlin: Duncker \& Humblot, 2006.

WILLOWEIT, Dietmar. "Dominium und Proprietas", Historisches Jahrbuch, n. 94, pp. 131-156.

ZAMORA, Romina. Casa poblada y buen gobierno: oeconomia católica y servicio personal en San Miguel de Tucumán (siglo XVIII). Buenos Aires: Prometeo Libros, 2017.

ZEMON DAVIS, Natalie. O retorno de Martin Guerre. Rio de Janeiro: Paz e Terra, 1987. ."On the Lame", The American Historical Review, vol. 93, n. 3, 1988, pp. 572-603.

ZIMMERMANN, Fernanda. "Armação baleeira da Lagoinha: uma grande unidade escravista". MAMIGONIAN, Beatriz Gallotti; ZIMMERMANN, Joseane Vidal (organizadoras). História diversa: africanos e afrodescendentes na Ilha de Santa Catarina. Florianópolis: Editora da UFSC, 2013, pp. 43-68. 